\title{
The Dynamics of Chromosome Organization and Gene Regulation
}

\author{
David L. Spector \\ Cold Spring Harbor Laboratory, One Bungtown Road, Cold Spring Harbor, New York \\ 11724; email: spector@cshl.org
}

Key Words gene expression, transcription, nuclear structure, nuclear dynamics

Abstract With the sequence of the human genome now complete, studies must focus on how the genome is functionally organized within the confines of the cell nucleus and the dynamic interplay between the genome and its regulatory factors to effectively control gene expression and silencing. In this review I describe our current state of knowledge with regard to the organization of chromosomes within the nucleus and the positioning of active versus inactive genes. In addition, I discuss studies on the dynamics of chromosomes and specific genetic loci within living cells and its relationship to gene activity and the cell cycle. Furthermore, our current understanding of the distribution and dynamics of RNA polymerase II transcription factors is discussed in relation to chromosomal loci and other nuclear domains.

\section{CONTENTS}

INTRODUCTION . . . . . . . . . . . . . . . . . . . . . . . . . . . 574

ORGANIZATION OF THE GENOME IN THE INTERPHASE NUCLEUS . . . . 574

Chromosome Territories . . . . . . . . . . . . . . . . . . . . . . . . . . . . 574

Positioning of Active Versus Inactive Genes Within Chromosome Territories . . 579

CHROMOSOME DYNAMICS . . . . . . . . . . . . . . . . . . . 580

Dynamics of Chromosomal Regions and Genetic Loci in Living Cells. . . . . . 581

DISTRIBUTION OF RNA POLYMERASE II TRANSCRIPTION SITES . . . . . . 584

ORGANIZATION OF TRANSCRIPTION SITES WITHIN CHROMOSOME

TERRITORIES . . . . . . . . . . . . . . . . . . . . . . . . . . . . 586

TRANSCRIPTION FACTOR LOCALIZATION . . . . . . . . . . . . . . . . 586

Dynamic Interactions with the Genome . . . . . . . . . . . . . . . . . . . . 586

Nuclear Domains and Transcription Factor Localization . . . . . . . . . . . . . . . 588

TRANSLATION IN THE NUCLEUS . . . . . . . . . . . . . . . . . . . . . . 594

GENE SILENCING AND NUCLEAR POSITIONING . . . . . . . . . . . . . . . . . 594

The Inactive X Chromosome . . . . . . . . . . . . . . . . . . . . . . . . . 595

Repositioning to Pericentric Heterochromatin . . . . . . . . . . . . . . . . . 595

Telomeres and the Nuclear Periphery . . . . . . . . . . . . . . . . . . . . . . . . 598

The Nuclear Periphery and Gene Activity . . . . . . . . . . . . . . . . . . 599 
REESTABLISHING THE GENE EXPRESSION MACHINERY AFTER

MITOSIS . . . . . . . . . . . . . . . . . . . . . . . . . 599

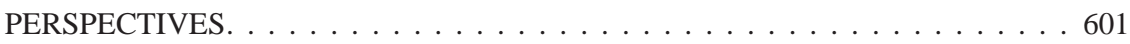

\section{INTRODUCTION}

The completion of the human genome sequence has thus far indicated an estimate of 30,000-75,000 genes, distributed among 3.2 billion basepairs of DNA that is packaged into a higher-order chromatin structure [reviewed in (1-4)]. These genes are arranged in the human interphase nucleus among the 46 chromosome territories such that they are readily accessible to transcriptional regulators that will mediate their expression or repression. All of this regulation takes place within the confines of the cell nucleus having an average volume of 600-1500 $\mu \mathrm{m}^{3}$. In addition, for cells exhibiting an open mitosis (i.e., mammalian, Drosophila), this organization is disassembled and then reassembled during each cell cycle. Determining how nuclear functions are organized and coordinated, both spatially and temporally, is central to understanding the proper workings of the cell and the alterations that are associated with various diseases. Recent advances in the areas of probe development [reviewed in $(5,6)]$ as well as microscopy have given us an unprecedented opportunity to visualize aspects of gene expression and dynamics at high resolution and/or in the context of the living cell. Such approaches that capitalize on previous biochemical and molecular advances allow one to delve into the inner workings of the nucleus in ways that could not have been anticipated a decade ago. In this review, I concentrate on the dynamic organization of the genome and its associated regulatory factors within the cell nucleus, focusing on the interplay between nuclear organization and RNA polymerase II transcription. For a more detailed analysis of additional aspects of nuclear structure/function the reader is directed to other reviews (7-13).

\section{ORGANIZATION OF THE GENOME IN THE INTERPHASE NUCLEUS}

\section{Chromosome Territories}

DNA is packaged into a higher-order chromatin structure, via its associations with histones and other nonhistone proteins, that directly impacts on gene expression [reviewed in (11)]. Early on, studies by Rabl and Boveri suggested that chromatin was not randomly organized within the interphase nucleus but occupied distinct territories. Rabl suggested that chromosomes in plant cells occupy discrete domains throughout interphase that reflect their mitotic orientation (14). Boveri confirmed these studies by showing that chromosomes maintained relatively fixed positions in the nuclei of Ascaris eggs (15). Furthermore, these studies suggested that telomeres were attached to the nuclear envelope on 
one side of the nucleus and centromeres were attached on the opposite nuclear side; this became known as a Rabl configuration. One of the most dramatic cases for interphase chromosome organization, and how chromosomes contribute to the assembly of a nuclear domain, comes from studies of nucleoli [reviewed in (13)]. In a classic study reported in 1934, Barbara McClintock identified a densely stained chromosomal region that she named the nucleolar-organizing body or element, and that we today refer to as the nucleolar-organizing region (NORs) (17). She went on to relate this chromosomal region to both the number and the type of nucleoli present in mutant strains of maize. In human cells, rDNA genes are clustered in the NORs of five pairs of acrocentric chromosomes (chromosomes 13, 14, 15, 21, and 22). At the end of mitosis, in HeLa cells, 6 of the 10 NORs become transcriptionally active and subsequently both the active and inactive NORs fuse to form the nucleoli.

More recently, numerous studies have readdressed the initial questions asked by Rabl and Boveri in a variety of systems at significantly higher resolution. In a groundbreaking study, Cremer et al. (18) showed that laser UV microirradiation of specific interphase nuclear areas in Chinese hamster cells damaged discrete chromosomal regions, suggesting that the genome is organized during interphase and provided some of the earliest insight into the concept of interphase chromosome territories. Early studies in Drosophila, examining polytene chromosomes differentially stained with vital dyes in conjunction with optical sectioning methods, have revealed these chromosomes to be closely associated with the inner surface of the nuclear membrane and to contact the membrane at specific sites (19-21). Furthermore, chromosomes were shown to occupy distinct territories within diploid and polytene nuclei and to spiral with the same handedness through the nucleus (21-23). In an elegant study, Sedat and co-workers (24) presented evidence for specific positioning of euchromatic loci within interphase nuclei of Drosophila embryos. These investigators used fluorescence in situ hybridization (FISH) to map the three-dimensional position of 42 DNA probes on a single interphase chromosome (24). Fourteen of 32 probes to euchromatic loci showed a nonrandom peripheral localization. Of six heterochromatic loci probed, only two, the AATAC satellite and the rDNA locus, were nuclear envelope associated, whereas four other loci were not associated with the nuclear periphery. Further analysis of the nuclear positions of these loci showed that the interphase nucleus in Drosophila is strongly polarized in a Rabl configuration that, taken together with specific targeting to the nuclear envelope or to the nuclear interior, results in each locus occupying a specific and reproducible position within the nucleus (24). Based upon the mapping of nuclear envelope contacts, it was estimated that there are on the order of 15 nuclear envelope interaction sites per chromosome arm, or a total of 150 nuclear envelope association sites per diploid Drosophila nucleus. These nuclear envelope association sites would be spaced on average 1-2 Mb apart and could thus define the boundaries of large loop domains tethered to the nuclear envelope in interphase. The nuclear envelope association sites were not found to strictly 


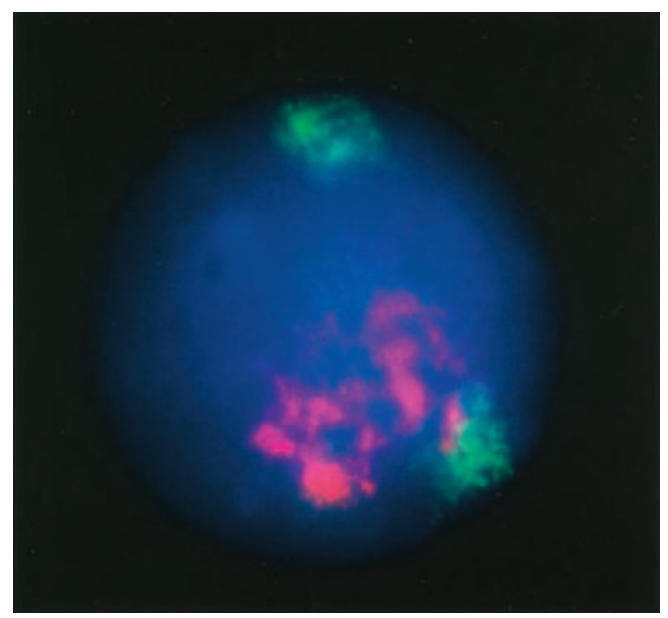

Figure 1 Fluorescence in situ hybridization to a human primary peripheral blood lymphocyte showing the peripheral localization of gene-poor chromosomes 18 (green) and the more internal localization of gene-rich chromosomes 19 (red). Note the more decondensed state of the gene-rich chromosomes. Total DNA is stained with DAPI. Photo courtesy of Wendy Bickmore, MRC Human Genetics Unit, United Kingdom.

correlate with scaffold-attachment regions, heterochromatin, or binding sites of known chromatin proteins (24).

Although the Rabl configuration of chromosomes is generally not observed in human cell nuclei, several groups have examined the organization of human chromosomes in interphase nuclei with the goal of identifying other organizational principles. Using probes specific for individual human chromosomes, and fluorescence in situ hybridization, it was shown early on that each chromosome occupies an individual interphase domain referred to as a chromosome territory (25-29). These territories occupy discrete and nonoverlapping nuclear regions (30), and in mammalian cells, homologous chromosome territories are usually not adjacent. Although repeatedly examined, the idea of a precise ordered positioning of human chromosomes is still somewhat controversial (31-33). However, in an extensive study, Bickmore and colleagues analyzed the nuclear organization of every human chromosome in diploid lymphoblasts and primary fibroblasts $(34,35)$. They found that most gene-rich chromosomes concentrate at more internal nuclear regions, whereas the more gene-poor chromosomes are located toward the nuclear periphery (Figure 1). These arrangements of chromosomes are established early in the cell cycle and are maintained throughout interphase (34). However, no statistically significant relationship between physical chromosome size (base pairs) and nuclear position was found in this study. Furthermore, chromosome subnuclear localization does not appear to be determined by the centromeres, as, remarkably, the distinctive localization observed 
is retained by regions of the chromosome arms that are translocated to chromosomes associated with reciprocal nuclear regions (34). Interestingly, in quiescent or senescent cells, gene-poor human chromosome 18 was shown to move from a location at the nuclear periphery to a more internal site in the nucleus (36). Intriguingly, the chromosome moves back toward the nuclear periphery during a 2-4 h period of time as quiescent cells enter the G1 phase of the cell cycle. Based upon these findings, the authors suggest that the spatial organization of the genome is plastic, potentially leading to the ability of quiescent nuclei to be more amenable to reprogramming $(36,37)$. In a parallel study, Cremer and colleagues performed a quantitative comparison of chromosome arrangements in flatellipsoid nuclei of human amniotic fluid cells and fibroblasts and in spherical B and T lymphocytes (38). Similar to that observed in spherically shaped lymphocyte nuclei by the Bickmore laboratory, a preferential positioning of small gene-dense chromosome territories was observed in the three-dimensional nuclear interior, whereas the gene-poor small chromosomes were peripherally localized. However, in contrast to that observed by the Bickmore group, large chromosomes were also preferentially located toward the nuclear periphery (38). The chicken karyotype represents an interesting example of chromosome organization. Chicken cells contain 9 pairs of gene-poor macrochromosomes and 30 pairs of gene-rich microchromosomes. Although the microchromosomes represent only $23 \%$ of the chicken genome, they contain $50 \%$ of its genes (39). In chicken fibroblasts and neurons, the gene-rich chromosomes are concentrated in the nuclear interior, whereas gene-poor chromosomes are located in peripheral nuclear regions (39). Gene density-correlated radial chromosome arrangements have been conserved during evolution of the higher-primate genome dating back an estimated 30-40 million years (40). In the ellipsoid nuclei of amniotic fluid cells and fibroblasts, all tested chromosome territories showed association with the upper and/or lower part of the nuclear envelope (38). Small chromosomes were located toward the center of the nuclear projection, whereas large chromosomes were located toward the nuclear periphery (38). These differences observed on the basis of chromosome positioning may reflect the different approaches used in sample preparation and/or may be indicative of the degree of dynamics of chromosome territories among different cell populations.

The specific interactions that mediate the nuclear position of a particular chromosome territory have not yet been identified. However, the nuclear envelope and nuclear lamina stand out as possible candidates based on convincing evidence that they participate in other aspects of nuclear organization [reviewed in (41)]. Numerous pathologies have recently surfaced with regard to mutations in protein constituents of the nuclear envelope/lamina (42). In one such disease, X-linked Emery-Dreifuss muscular dystrophy (X-EDMD), mutations have been identified in the emerin gene (43). Emerin is a type II integral membrane protein localized to the inner nuclear envelope and most X-EDMD-associated mutations result in a loss of emerin protein at the nuclear membrane [reviewed in (44)]. One disease model has suggested the inability of emerin-null cells to sequester 
inactive chromatin at the nuclear periphery, thereby leading to altered regulation of gene expression [reviewed in (44)]. To examine this possibility, Boyle et al. determined chromosomal positions in lymphoblast cells from an individual with a null mutation in emerin (35). However, the spatial positioning of chromosome territories in such cells was not significantly different from that of their normal counterparts. Therefore, although emerin has thus far not been implicated in chromosomal positioning, other components of the nuclear envelope/lamina have yet to be tested.

Aside from physical associations, changes in chromatin structure, as reflected by protein modifications and/or associations, may also play a role in the positioning of chromosomes. In a recent study, Almouzni and colleagues examined the long-term effects of deacetylase inhibitors on the maintenance and nuclear compartmentalization of pericentric heterochromatin in mouse cells (45). Incubation of cells with the histone deacetylase inhibitor, trichostatin A (TSA), for five days selectively induced large-scale movements of centromeric and pericentric heterochromatin to the nuclear periphery without any significant effect on either its methylation status or telomere position. In addition, these regions lost their association with heterochromatin 1 (HP1) proteins, which became distributed throughout the nucleoplasm (45). Interestingly, upon drug removal $(20 \mathrm{~h})$ these chromatin regions resumed their typical nuclear positions and their association with HP1. Based upon the necessary lengthy incubation with TSA, prior to observing the effects, the authors posit that several cell divisions may be required to destabilize the HP1 population. As each round of DNA replication would dilute by half the parental nonacetylated histones with newly incorporated acetylated histones, eventually a complete loss of HP1 would be achieved (45). The observed reversibility of the TSA effect in mammalian cells was not found to be the case in Schizosaccharomyces pombe, where TSA treatment resulted in a delocalization of the HP1 homologue and severe defects in centromeric regions and chromosome segregation during mitosis $(46,47)$. Almouzni and colleagues suggest that this difference may relate to a lack of methylation of pericentric DNA in S. pombe, as DNA methylation has been shown to induce histone deacetylation in mammalian cells and could thus result in the observed recovery after TSA removal (45).

In addition to pursuing the associations that mediate chromosome territory position, several groups have assessed the parameters involved in the organization of individual chromosome territories. Upon increasing concentrations of salt, up to $1.8 \mathrm{M}$, gene-poor chromosome 18 was released from the nuclear remnants, whereas gene-rich chromosome 19 remained in the center of the nuclei, suggesting a differential association with the nuclear substructure based upon gene density (34). Furthermore, gene-rich chromosome 19 assumed a more compact structure in the absence of transcription, although its overall position in the nucleus was not altered (34). In a separate study, Berezney and colleagues found chromosome territory organization to be maintained despite the extraction of greater than $90 \%$ of the histones and other soluble nuclear proteins in DNA-rich 
nuclear matrix preparations. Interestingly, upon complete extraction of internal nuclear matrix components with RNase treatment followed by $2 \mathrm{M} \mathrm{NaCl}$, a disruption of higher-order chromosome territory architecture was achieved, suggesting a role for RNA/RNP in chromosome organization (48). In conjunction with the observed chromosome disruption, a small set of 40-90-kD acidic proteins, distinct from the major nuclear matrix proteins, was released (48). These proteins are being pursued as potential mediators of chromosome territory organization. Based upon the effect of RNase treatment, it is tempting to speculate that stable nuclear RNAs and/or RNPs may play a role in the maintenance of interphase chromosome organization. Interestingly, Almouzni and colleagues have recently identified the involvement of RNA in mediating the interaction of heterochromatin protein 1 (HP1) and methylation of H3 lysine-9 with pericentric heterochromatin (49).

\section{Positioning of Active Versus Inactive Genes Within Chromosome Territories}

An extensive effort has focused on examining the position of individual genes and/or chromosomal regions within chromosome territories to assess the relationship of gene activity to chromosomal position. Several studies have suggested that inactive genes may be located in interior regions of chromosomal territories and active genes may concentrate along the periphery (30,50-52), adjacent to nonchromosomal nucleoplasmic space, termed the interchromosome domain compartment (ICD) $(53,54)$. However, other studies indicate that this type of organization may not be a general trend $(55,56)$. In addition, an overall analysis of gene-rich (GC-rich) chromosomal regions indicates that they are distributed throughout chromosomal territories with no preference for their periphery (57). Interestingly, the gene-rich major histocompatibility complex (MHC), at human chromosome 6p21.3, was localized external to the chromosome 6 territory or to large chromosomal loops that extend from the surface of the bulk chromosome 6 territory (52). Transcriptional upregulation of the MHC class II genes by interferon-gamma resulted in an increase in the frequency with which this gene cluster appeared on external chromosomal loops (52). A similar organization was observed for the human epidermal differentiation complex at 1q21, which contains genes that are involved in keratinocyte differentiation (58). This region appears to extend outside of the chromosome 1 territory in keratinocytes where the genes are highly expressed, but not in lymphoblasts where they are silent (58). The amplified and highly expressed ERBB2 genes have also been observed to extend from the chromosome 17 territories in a breast cancer cell line (59). While the position of a number of active genes have been mapped with respect to their corresponding chromosome territories $(50,51,60)$, the most extensive analysis has been done on a $\sim 1-\mathrm{Mb}$ region of human chromosome $11 \mathrm{p} 13$ and the syntenic region in the mouse (61). This region of chromosome 11 contains ubiquitously expressed genes as well as genes whose expression is tissue type specific (62-64). In addition, large intergenic stretches of DNA are 
present within this region $(62,63)$. All the $11 \mathrm{p} 13$ loci studied, including expressed genes, were located within the chromosome territory, compared with a locus from $11 \mathrm{p} 15$ that localized to the territory edge (61). Similar observations were made with its region of conserved synteny in the mouse. Furthermore, tissue-restricted genes were not relocated to the periphery of the respective chromosome territory in expressing cells (61). Based upon these findings, it was concluded that gross remodeling of chromosome territories does not occur to accommodate relatively small changes in gene expression in mammalian cells (61). Instead, local changes in chromatin fiber conformation are likely to be associated with gene expression $(65,66)$. The respective factors involved in this process are likely to have accessibility to neighborhoods throughout the chromosome territory, with local changes in protein modification and chromatin structure regulating the binding affinities and subsequent gene expression profiles.

\section{CHROMOSOME DYNAMICS}

Although individual chromosome territories have been localized in fixed cells to discrete nuclear regions, several early studies provided initial evidence to support the concept that these territories are dynamic in the interphase nucleus and that their positions may be cell cycle dependent. Using a composite probe to chromosome 8, Ferguson \& Ward showed by in situ hybridization that in G1 cells chromosome 8 centromeres localized adjacent to the nuclear periphery and the chromosomal arms extended toward the nuclear interior (67). However, in G2 cells the chromosome reoriented itself; the centromeres were internal, and the chromosomal arms extended toward the nuclear periphery. A similar redistribution was observed in brain tumor cells where centromeres were dispersed during G1 and S-phase and became clustered toward the nuclear interior during G2 (68). Examination of chromosome positioning in CNS nuclei in larval Drosophila indicated large chromosomal movements in diploid interphase nuclei (69). At the onset of S-phase, an increased separation was seen between proximal and distal positions of a long chromosome arm (69). However, a study of centromeres in living human cells using a CENP-B-GFP fusion protein found that centromeres in HeLa cells were predominantly stationary, although movement of individual or small groups of centromeres was occasionally observed at very slow rates of $7-10 \mu \mathrm{m} / \mathrm{h}$ (70). Therefore, different paradigms are likely to exist for chromosome movement in different cell types within an organism, as well as in similar cell types among different organisms, depending upon the overall chromatin organization within the respective cell type. One of the most provocative studies demonstrating a correlation between chromosome position and cell physiology comes from work on human epileptic foci (27). In normal male cortical neurons, the $\mathrm{X}$ chromosome was localized to the nuclear periphery. However, when cells in an electrophysiologically defined seizure focus were observed, there was a dramatic increase from $\sim 7 \%$ to $45 \%$ in the number of cells exhibiting internal 
nuclear localization of the $\mathrm{X}$ chromosome (27). A similar observation was previously reported in neurons after $8 \mathrm{~h}$ of electrical stimulation (71). However, more recent live cell studies in tissue culture cells, examining the dynamics of fluorescently labeled chromosomes, have concluded that interphase chromosome territories in general undergo only a limited large-scale translational motion $(72-75)$.

\section{Dynamics of Chromosomal Regions and Genetic Loci in Living Cells}

In a significant breakthrough, Belmont and coworkers developed an approach, based upon the use of the lac operator/repressor system, to directly visualize chromatin organization and dynamics in living cells (76). By introducing a lac operator array into Chinese hamster ovary cells with the dihydrofolate reductase gene and amplifying it through methotrexate selection (76), a stable cell line was selected containing a $\sim 90-\mathrm{Mbp}$ chromosomal array that can be visualized using a GFP-lac repressor fusion protein. The array formed a late-replicating homogeneously staining region (HSR) (77). Cell cycle analysis indicated that the integration site was peripherally localized throughout most of interphase. However, during several hours in mid- to late S-phase, the HSR decondensed and moved toward the nuclear interior correlated with its DNA replication (77). Using this system the Belmont group has been able to directly visualize activator binding in living cells, and they have found that chromatin decondensation occurs upon activator binding and in the absence of transcription (78). However, studies using a tandem array ( $\geq 2 \mathrm{Mbp}$ ) of the mouse mammary tumor virus (MMTV) promoter driving a ras reporter have shown that this array does require transcription for chromatin decondensation (79). Therefore, different loci may respond to different signals for chromatin decondensation. In a separate study, using a cell line with a smaller integration (150-300 Kbp), VP16 targeting to the locus was also shown to induce its movement from the nuclear periphery to a more internal nuclear region (80), suggesting that internal nuclear regions may be more amenable to potentially active loci. Furthermore, the recruitment of several histone acetyltransferases, including GCN5, P/CAF, and p300/CBP, and hyperacetylation of all core histones was observed (78). Examination of the extended chromosome fibers by light and electron microscopy supports the existence of a folded chromonema model based upon $\sim 100$-nm chromonema fibers formed by compaction of $10-\mathrm{nm}$ and $30-\mathrm{nm}$ chromatin fibers $(76,78)$.

The lac operator/repressor system has provided an unprecedented approach to visualizing chromatin organization and remodeling in real time. An elaboration of this approach has allowed for the development of a cell system that offers direct read-out of gene expression in living cells. Using the lac operator/repressor system and two color variants of GFP, Spector and colleagues have developed a system to visualize a genetic locus and its protein product directly in living cells (66). Dynamic morphological changes in chromatin structure, from a condensed 

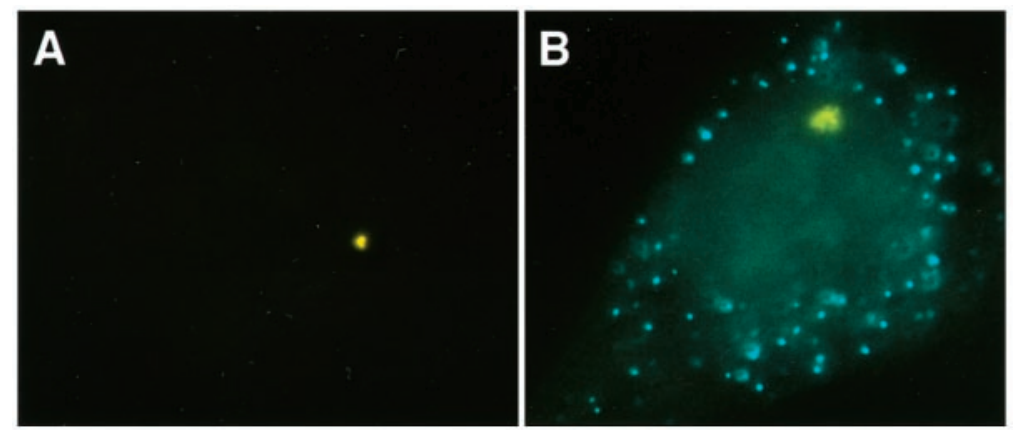

Figure 2 Localization of a stably integrated regulatable genetic locus in the "off" $(A)$ and "on" $(B)$ states using the lac operator/repressor system (66). In the "off" position the locus is visualized via CFP-lac repressor protein as a single dot in each interphase nucleus $(A)$. Upon transcriptional activation the locus decondenses and the protein product of the transcription unit is localized to cytoplasmic peroxisomes $(B)$. The protein product is visualized via a CFP-peroxisome targeting signal fusion protein.

to an open structure, were observed during gene activation, and targeting of a cyan fluorescent protein reporter to the peroxisomes was directly visualized in living cells (Figure 2) (66).

In order to monitor the movements of individual genetic loci on different human chromosomes, Bickmore and co-workers randomly integrated a lac operator array into the human genome and selected clones that contained a single integration site of the array (128-mer array) at different chromosomal positions (81). In general, chromatin associated with the nucleolus or nuclear periphery was more restricted in its movement than chromatin associated with other nucleoplasmic regions, indicating that these structures may act as anchoring sites (81). For example, 13q22, a region associated with the nuclear periphery, exhibited a maximum range of movement of $0.9 \mu \mathrm{m}$, whereas $5 \mathrm{p} 14$, a nucleoplasmic locus, exhibited a maximum movement of $1.5 \mu \mathrm{m}$. Interestingly, the 5 p14 and 3q26.2 loci exhibited similar diffusion coefficients $\left(1.25 \times 10^{-4}\right.$ $\mu \mathrm{m}^{2} / \mathrm{s}$ ), although their gene density and replication timing were determined to be different. The 5p14 locus resides in a $\mathrm{G}$ band (gene poor, late replicating), whereas $3 q 26.2$ is in an $\mathrm{R}$ band (gene dense, early replicating). The diffusion coefficient for human loci (81) was estimated to be fourfold lower than that estimated for budding yeast centromeres, which move considerably less than coding regions $(82,83)$. This constrained motion may relate to associations with nuclear structures, with the relative concentration of DNA relative to the nuclear volume, and/or the significantly larger amount of heterochromatin present in human cells that may act as anchoring sites.

Several studies examining chromatin dynamics in Drosophila have also identified constrained chromatin movements. An earlier study in Drosophila 
embryos, examining a topoisomerase II-enriched 359-base pair repeat block of heterochromatin on the $\mathrm{X}$ chromosome (82), revealed that this region of chromatin undergoes significant diffusive Brownian motion with a diffusion constant of $2.0 \mathrm{X} \times 10^{-7} \mu \mathrm{m}^{2} / \mathrm{s}$ within a restricted radius of $\sim 0.9 \mu \mathrm{m}$ (82). Interestingly, this chromatin region is a scaffold-associated region (SAR) in Drosophila. More recently, a study to track chromosome motion in Drosophila spermatocytes (73) using a lac operator array revealed multiple levels of constrained motion. Over short time intervals of a few seconds, chromatin movement was restricted to submicron-sized regions $(0.3 \mu \mathrm{m} / \mathrm{s})$ of the nucleus. Over time periods of an hour or more, loci were found to be considerably more mobile, with a range of several microns. Interestingly, this long-range motion was restricted to early G2 spermatocytes and was not observed later in G2, as cells approached meiotic prophase. The overall chromatin movements were consistent with a random walk as no directed movements were observed (73). The average diffusion coefficient of single sites in early nuclei was $\sim 1.0 \times 10^{-3} \mu \mathrm{m}^{2} / \mathrm{s}$, about one order of magnitude greater than that observed for a centromeric domain in yeast (82). Although specific chromosomal regions demonstrate various levels of confined movement, the overall position of chromosomes was constrained to specific nuclear territories.

A similar approach to examine chromatin dynamics in Saccharomyces cerevisiae evaluated specific chromosomal sites that were tagged with a lac operator array at the LEU2 locus near the centromere of chromosome III (82). Using single particle tracking methods, the chromatin was found to undergo diffusive Brownian motion with a diffusion constant of $5.0 \times 10^{-8} \mu \mathrm{m}^{2} / \mathrm{s}$ within a restricted radius of less than $0.3 \mu \mathrm{m}$, a region that corresponds to $\sim 1 \%$ of the nuclear volume (82). Interestingly, cells treated with a microtubule depolymerizing drug, nocodazole, resulted in less-confined chromatin diffusion (82). However, the motion of noncentromeric sites was not affected by such drugs (83). In a more recent study, examining G1 nuclei in $S$. cerevisiae, early and late origins of replication exhibited large rapid movements $(>0.5 \mu \mathrm{m}$ in $10 \mathrm{~s})$ that surprisingly were ATP dependent, whereas smaller saltatory movements $(<0.2$ $\mu \mathrm{m})$, similar in range to those observed in Drosophila (73), were observed throughout interphase (83). Given that the yeast nucleus measures $\sim 2.0 \mu \mathrm{m}$ in diameter, these $0.5 \mu \mathrm{m}$ movements are extremely significant and demonstrate that chromosomal regions can move within large nuclear areas over short time periods. The large movements were proposed to reflect the action of ATPdependent enzymes involved in transcription and chromatin remodeling (83). These rapid movements became constrained in S-phase, and they dropped fourfold in G1 cells, as cell density increased to $\sim 2 \times 10^{7}$ cells $/ \mathrm{ml}$, or just before the diauxic shift from fermentative to oxidative metabolism (83). However, telomeres and centromeres were found to provide replication-independent constraint on chromatin movement in both G1 and S-phase cells, supporting the concept that periodic sites along a chromosome may tether it and thereby confine its position within a restricted nuclear region (83). The large rapid movements 
observed for regions of yeast chromosomes have been suggested to indicate that chromosome territories are loosely arranged. Given that yeast contain little heterochromatin, their chromosomes may contain fewer anchoring sites. The dynamics of chromatin in vivo may in part reflect nuclear volume: DNA length, as reduction in chromatin movement correlates with reduced nuclear volume in several instances $(73,81,83)$.

An alternative live cell approach, which allows the visualization of individual or a few different chromatid territories in living cells, has made use of microinjection of the fluorescent thymidine analog Cy3-AP3-dUTP into the nuclei of cultured human cells (84). The analog incorporates into replicating DNA in S-phase, and after growth for several cell cycles random segregation of labeled and unlabeled chromatids into daughter nuclei results in nuclei exhibiting individual labeled chromatid territories that can be studied in living cells. However, as compared to the use of the lac operator/repressor system described above, the chromatid(s) that is labeled is randomly selected and not stable. Such studies have indicated that chromatid territories are composed of subcompartments with diameters ranging between 400-800 nm, referred to as subchromosomal foci. The foci are composed of either early or late-replicating chromatin; similar size replication foci have been reported previously during S-phase (85). Time-lapse imaging has indicated changes in the shape and positioning of individual chromatid territories, repositioning of subchromosomal foci within stable territories, and changes in patterns of folding and extension of the foci over time (84).

\section{DISTRIBUTION OF RNA POLYMERASE II TRANSCRIPTION SITES}

Several approaches have been used to examine the organization of transcription sites within the nuclei of mammalian cells. In a series of now classic studies, Fakan and colleagues used ${ }^{3} \mathrm{H}$-uridine incorporation, after short pulses, combined with electron microscopic autoradiography and observed non-nucleolar transcription sites to be distributed throughout the nucleoplasm of mammalian cells with a preference for the borders of condensed chromatin (86-88). In addition, transcription sites are also observed on the periphery of interchromatin granule clusters and at other nucleoplasmic regions $(89,90)$. Transcription sites are specifically associated with nuclear structures termed perichromatin fibrils, which are thought to represent nascent transcripts based upon the pulse labeling experiments as well as antibody labeling for transcription and pre-mRNA processing factors [reviewed in $(7,91)$ ]. Perichromatin fibrils are RNase sensitive and their appearance is inhibited by pretreatment with actinomycin D or $\alpha$-amanitin [reviewed in (92)]. More recent studies have used Br-UTP incorporation (93, 94) to examine the localization of transcription sites both at the immunofluorescence and electron microscopic levels (Figure 3). Using this approach, Pombo et 


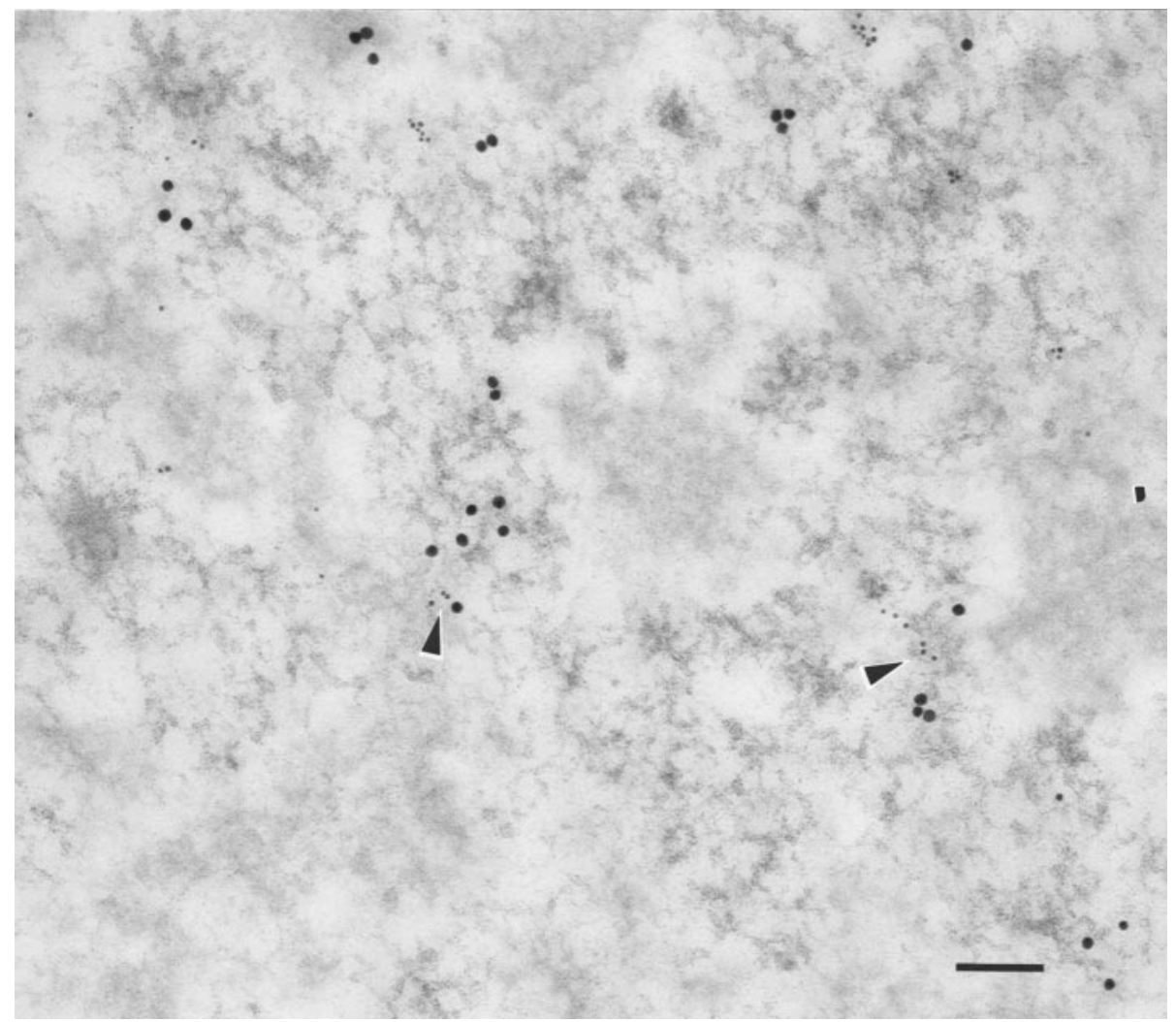

Figure 3 Human bladder carcinoma T24 cells were microinjected with Br-UTP and incubated for $12 \mathrm{~min}$ to label transcription sites. Double-labeling with mouse anti-BrdU antibody (6-nm colloidal gold particles) and chicken anti-RNA polymerase II antibody (15-nm colloidal gold particles) shows that both localize at perichromatin fibrils (arrowheads). Bar equals $100 \mathrm{~nm}$. Photo courtesy of D. Cmarko \& S. Fakan, University of Lausanne, Switzerland.

al. (95) identified $\sim 10,000$ non-nucleolar transcription sites in HeLa cell nuclei. Of these $\sim 8000$ are thought to represent RNA pol II transcription sites and $\sim 2000$ represent RNA pol III transcription sites. Each of these sites measures $\sim 50 \mathrm{~nm}$ in diameter and has been termed a transcription factory (96), as the authors propose a model in which RNA polymerases are associated with the nuclear skeleton-forming factories, and templates surround the factories. Transcripts are extruded from the factories upon passage of templates through the positionally fixed polymerases (97).

Numerous studies have indicated that active genes as well as many transcription factors are associated with the nuclear matrix or nucleoskeleton [reviewed in (98-102)]. Most interestingly, the nuclear lamins, an indisputable structural 
element of the nuclear periphery as well as internal nuclear regions [reviewed in (41)], have recently been shown to be necessary for RNA polymerase II transcription both in mammalian cells as well as in nuclei from Xenopus laevis (103). When lamins were disrupted in BHK cells or in nuclei from early Xenopus gastrulae by addition of a $\Delta$ N-terminal human lamin A $(\Delta N L A)$, a dominantnegative lamin mutant, the lamins formed abnormal nucleoplasmic aggregates (103). Br-UTP incorporation was dramatically decreased in these nuclei and TATA binding protein (TBP) was found in the nucleoplasmic aggregates. However, the distribution of Sp1, a RNA pol II gene-specific transcription factor, was not affected by addition of the $\triangle$ NLA nor was RNA pol I or pol III transcription. Based upon these data, the authors proposed that RNA pol II transcription and the distribution of TBP depend upon the maintenance of normal nuclear lamin organization (103).

\section{ORGANIZATION OF TRANSCRIPTION SITES WITHIN CHROMOSOME TERRITORIES}

To examine the overall relationship of transcription to the organization of chromosomal territories, Verschure et al. (56) combined chromosome painting, to identify a specific territory, with Br-UTP incorporation, to identify transcription sites. Confocal image stacks of hybridized chromosome paint probes indicated that chromosome territories are not compact structures, as had been previously implied; instead they appeared as open structures consisting of clusters of 300-450-nm domains that were sometimes interconnected, forming a thread-like, folded structure (56). The subdomains were surrounded by less intensely labeled areas. When such analysis was combined with Br-UTP labeling to localize nascent RNA, transcription sites were observed to extend throughout the territories of gene-rich chromosome 19 and the active $\mathrm{X}$ chromosome (Figure 4). Interestingly, newly synthesized RNA localized in those regions that labeled less intensely with the chromosome paint probes. Based upon these data, the authors propose that the interchromosomal domain space $(53,54,104)$ extends to regions within chromosome territories (56). A similar localization of transcription sites throughout chromosome territories in rapidly dividing wheat cell nuclei has been observed (55).

\section{TRANSCRIPTION FACTOR LOCALIZATION}

\section{Dynamic Interactions with the Genome}

Although many models of transcription based upon in vitro experiments implicate stable complexes that are bound to chromatin for relatively long periods of time [reviewed in (105)], recent data from live cell experiments indicate just the 

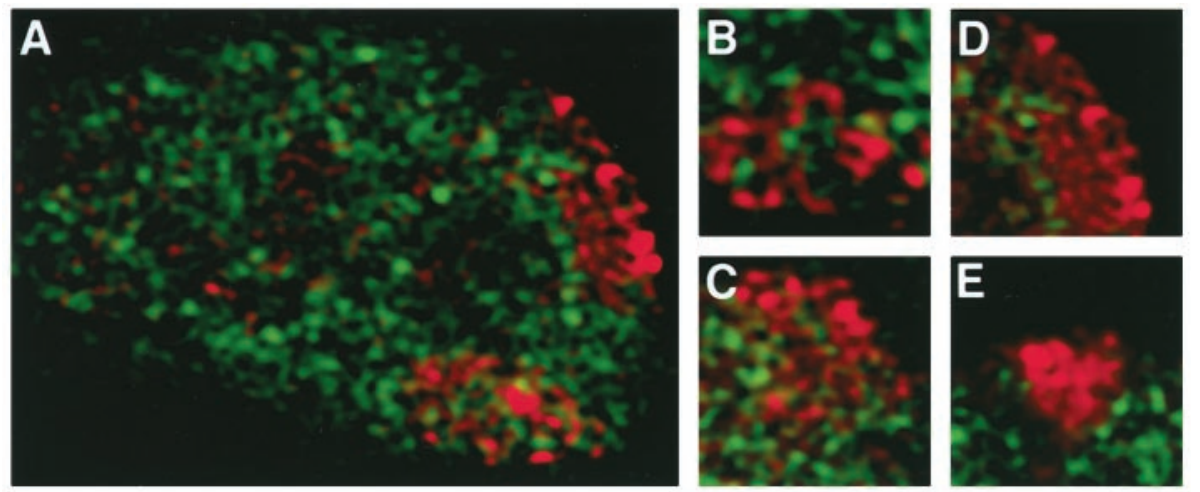

Figure 4 Confocal optical sections showing the distribution of transcription sites in relation to the two X-chromosome territories in human female primary fibroblasts. Nascent RNA was labeled by incorporation of Br-UTP (green) and the X-chromosome territories were labeled by FISH (red). Transcription sites occur as defined spots throughout one of the two $\mathrm{X}$-chromosome territories (most likely the active $\mathrm{X}$, panels $A, B$ ), whereas almost no transcription sites are observed in the other X-chromosome territory (most likely the inactive $\mathrm{X}$, panels $A, D$ ). An additional example of an active $\mathrm{X}$ territory (panel $C$ ) and inactive $\mathrm{X}$ territory (panel $E$ ) from a different nucleus are also shown. Chromosome territories have a distinct substructure, showing strongly labeled structures that are surrounded by less intensely labeled structures. The intensely labeled structures have a diameter in the range of $300-450 \mathrm{~nm}$. Nascent RNA preferentially accumulates between the intensely labeled structures, in the areas with little to no DNA FISH labeling. Reproduced from Verschure et al. The Journal of Cell Biology, 1999, 147:13-24, by copyright permission of The Rockefeller University Press.

contrary-highly dynamic interactions of factors with the chromatin substrate [reviewed in (106)]. Live cell imaging using GFP fused to several different transcription factors (107-109), as well as to histone H1 and the HMG 17, 14 proteins [reviewed in (12)], in combination with fluorescence recovery after photobleaching (FRAP) techniques, has shown that these nuclear proteins are highly dynamic, exhibiting rapid exchange rates, with occupancy times of minutes to a few seconds at their target substrates. In contrast, such studies have indicated that the core histones remain immobilized on chromatin for hours (110). In a groundbreaking study, the Hager group demonstrated that the glucocorticoid receptor undergoes rapid exchange, with a $t_{1 / 2}$ of $5 \mathrm{~s}$, between chromatin regulatory elements and the nucleoplasm in the presence of ligand (107). These data support a "hit-and-run" model of factor association with the response element, and ATP-dependent chromatin remodeling activities have been suggested to be involved in this rapid exchange of proteins (111). Mancini and colleagues found the unliganded estrogen receptor exhibited a rapid exchange, $t_{1 / 2}>1 \mathrm{~s}$, whereas agonist or partial agonist slowed recovery $\left(\mathrm{t}_{1 / 2} 5-6\right.$ 
s) $(108,113)$. Interestingly, the dynamics of the unliganded estrogen receptor was shown to be ATP and proteasome dependent (108). A similar degree of rapid dynamics has been observed between a receptor coactivator, SRC-1, or a general coregulator (CBP), and an estrogen-receptor-lac repressor fusion protein bound to a lac operator array (113). Furthermore, the identification of members of a chaperone complex at certain promoters has resulted in a model whereby molecular chaperones may be essential for promoting continuous disassembly of transcriptional regulatory complexes, resulting in the observed turnover and the ability to respond to signaling changes (114). For example, the p23 molecular chaperone can disrupt thyroid hormone receptor DNA complexes in vitro and appears to compete with a coactivator for association with the thyroid receptor ligand binding domain, resulting in opposing effects on the stability of the receptor-DNA interaction (115). Intriguingly, regardless of this rapid dynamics of factors, protein complexes can be visualized at specific promoters and within an increasing number of different nuclear organelles. The basis for maintaining the highly local concentrations of these factors such that steady-state levels form functional complexes and are easily observed in intact cells remains to be elucidated.

\section{Nuclear Domains and Transcription Factor Localization}

The localization of the large subunit of RNA pol II as well as a number of general transcription factors (GTFs) and promoter-specific transcription factors have been examined by immunofluorescence microscopy. Although, as expected, these factors localize at transcription sites that are distributed throughout the nucleoplasm in a fine punctate localization as described above, many of them have also been found concentrated in a number of different nuclear domains in which transcription has thus far not been reproducibly detected, except in the case of the OPT domain (116) (Figure 5). As compared to the localization of RNA pol II LS, the distribution of GTFs is somewhat more variable. Grande et al. (117) examined the localization of a number of GTFs including TFIIH (p62) and TFIIF (RAP74) and BRG1, a human homologue of the yeast SWI/SNF chromatin remodeling complex. All of these proteins are distributed in a fine punctate distribution throughout the nucleoplasm. Other promoter-specific transcription factors such as E2F-1 (117), GATA-1 (118), Oct1 (116), Pit-1 (119),

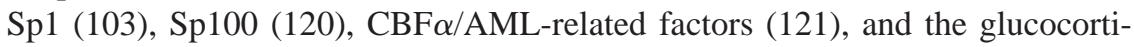
coid receptor (107) have also been localized throughout the nucleoplasm in a punctate distribution. Surprisingly, except for TFIIH, little correlation was observed between the localization of other GTFs and the localization of RNA pol II LS and transcription sites (117). In addition to this broad distribution, many transcription-related proteins also localize to other nuclear domains, such as nuclear speckles, the OPT domain (116), Cajal bodies $(122,123)$, promyelocytic leukemia (PML) nuclear bodies [reviewed in $(9,124)]$, and heat shock factor 1 (HSF1) granules $(125,126)$, as is discussed below. 


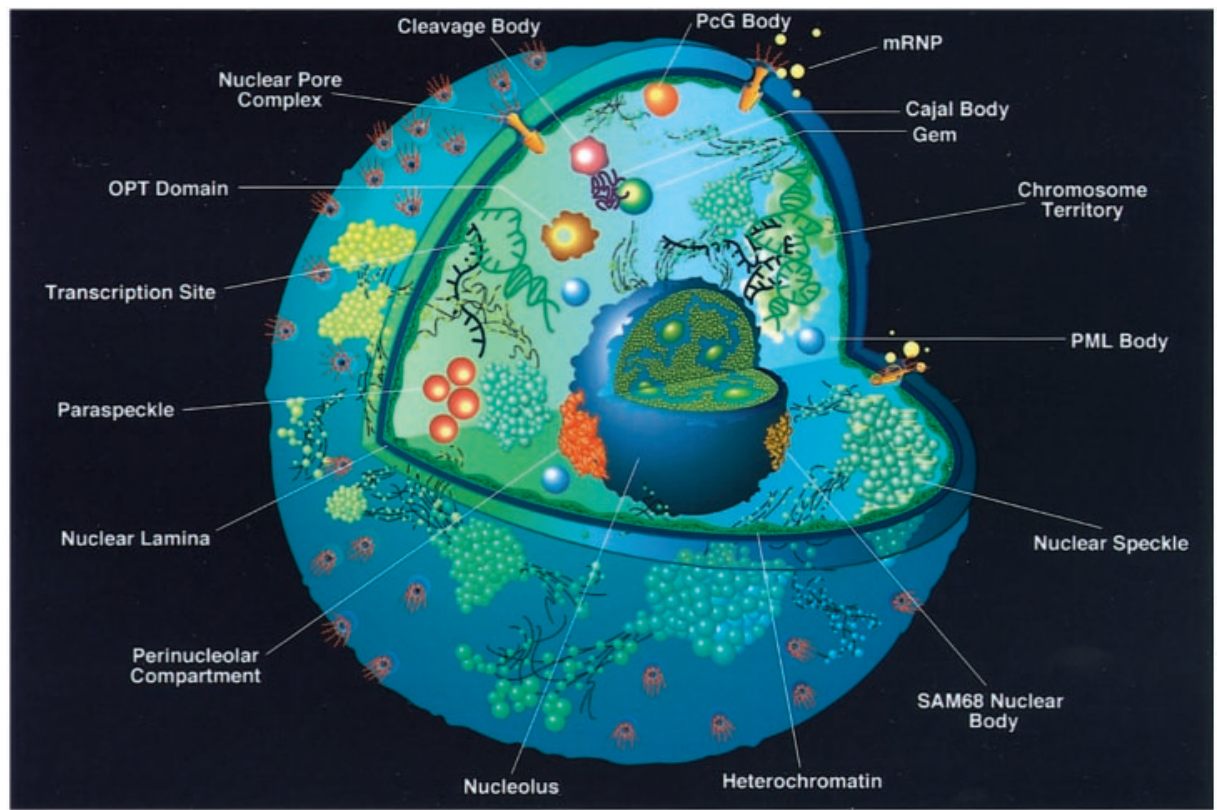

Figure 5 Cartoon of a mammalian cell nucleus showing the large number of nuclear domains that have been identified. Those involved in aspects of transcription or associated with transcription factors are discussed in the text.

THE SPECKLE CONNECTION The unphosphorylated or the serine-5 phosphorylated form of the large subunit of RNA pol II (RNA pol II LS) that is involved in transcriptional initiation is localized in a diffuse nuclear distribution that has considerable, but not complete, overlap with sites of transcription (Figure 3) $(117,127)$. The serine-2 phosphorylated form of RNA pol II LS, which is involved in elongation, is localized similarly, but in addition it is localized to nuclear speckles (Figure 5) when observed by immunofluorescence microscopy $(127,128)$. However, some studies have not observed an enrichment of RNA pol II LS in speckles [for example (117)]. These nuclear regions correspond to interchromatin granule clusters (IGCs), 0.5-1.0 $\mu$ m nuclear regions composed of granules each measuring 20-25 $\mathrm{nm}$ in diameter. IGCs have been implicated in the modification and/or assembly of premRNA splicing factors and possibly a subset of transcription factors (129-131). As transcription does not occur in IGCs and because this localization pattern of RNA pol II LS is primarily observed by labeling with one antibody, H5 (127), it has been suggested that this epitope may be present both on the elongating form of RNA pol II as well as on a form that is stored and/or in the process of being modified in IGCs prior to its recruitment to transcription sites. Biochemical characterization of the IGC proteome has identified several subunits of RNA pol II (132; N. Saitoh, P. 
Sacco-Bubulya \& D.L. Spector, in preparation), supporting the localization of at least a population of RNA pol II in these nuclear domains.

The Cdk9-cyclin T complex, also known as TAK/P-TEFb, is thought to be involved in transcriptional elongation via phosphorylation of the RNA pol II LS [reviewed in (133)]. This complex was found diffusely distributed throughout the nucleoplasm, with the exception of the nucleoli (134). In addition, a significant overlap between cyclin T1 and nuclear speckles was observed. A region in the central portion of the cyclin T1 protein was found to be important for this subnuclear targeting (134). However, Cdk9 was present in the vicinity of nuclear speckles but a direct overlap was limited (134). Surprisingly, Cdk9 and cyclin T1 also showed only a limited colocalization with RNA pol II at sites on polytene chromosomes in Drosophila (135). This lack of colocalization has been suggested to possibly be due to a dynamic and short-lived interaction of these proteins at transcription sites in vivo (135). Other members of the Cdk family, $\mathrm{Cdk} 7$ and $\mathrm{Cdk} 8$, which are involved in transcriptional regulation, are not found in nuclear speckles (136). Cdk7 was localized to Cajal bodies (Figure 5) in addition to being diffusely distributed throughout the nucleoplasm (136).

FBI-1 is a cellular POZ-domain-containing protein that binds to the HIV-1 LTR and associates with the HIV-1 transactivator protein Tat (137). FBI-1 has been found to partially colocalize with Tat and its cellular cofactor, P-TEFb, at nuclear speckles (138). In addition, a less soluble population of FBI-1 is distributed in a peripheral-speckle pattern that is dependent upon the FBI-1 DNA binding domain and active transcription (138). This distribution may be associated with active transcription sites (perichromatin fibrils) that are found on the periphery of IGCs $(139,140)$. The nucleosome binding protein HMG-17, which can alter the structure of chromatin and enhance transcription, has been localized in a pattern similar to that of FBI-1 (141).

OPT DOMAIN In addition to its diffuse distribution, in $\sim 30 \%$ of the HeLa cells examined, Oct1 occurs in a highly localized domain often located close to a nucleolus and measuring 1.0-1.5 $\mu \mathrm{m}$ in diameter (117). However, in normal human skin fibroblasts, Oct1 was found in four to six nuclear domains smaller than those observed in HeLa cells. Based upon the localization of Oct 1, PTF [PSE binding transcription factor, also known as SNAPc (snRNA-activating protein complex)], a complex involved in activating transcription of snRNA genes [reviewed in (142)], and the finding that transcription could be detected within this nuclear domain, the region was named the OPT domain (Figure 5) (116). RNA pol II as well as TBP (TATA binding protein) and Sp1 were also found within the OPT domain (116). These domains were found to contain transcripts generated by both RNA pol II and pol III (116). OPT domains assemble during G1 and disappear early in S-phase (116), and they coincide with a nuclear domain identified earlier as the polymorphic interphase karyosomal association (PIKA) domain (143). Interestingly, OPT domains are often associated with chromosome $6 \mathrm{p} 21$ and chromosome 7 , although they were not found 
associated with various Oct1- and PTF-dependent genes (i.e., U1 and U2 snRNAs, 7SK, hY RNA, histones) (116).

CAJAL BODIES Cajal bodies are nuclear organelles first identified as nucleolar accessory bodies by Santiago Ramón y Cajal (144), and they are thought to function in snRNP biogenesis (123). Populations of several transcription factors including TFIIF and TFIIH have been localized to Cajal bodies in HeLa cells (117). Cajal bodies are associated with histone genes as well as gene clusters encoding the U1, U2, and U3 snRNAs $(145,146)$, although the organization of genes in arrays is not necessary for Cajal body association, as several single-copy snRNA loci also have a statistical preference to localize with Cajal bodies (147). Interestingly, Matera and coworkers showed that artificial tandem arrays of U2 genes colocalized with Cajal bodies and the frequency of the colocalization was directly dependent upon the transcriptional activity of the array. The association was lost upon transcriptional inhibition or by promoter mutations (147). Importantly, the U2 coding region was required for the association, suggesting that the association may be mediated through the snRNA nascent transcripts or a polymerase complex (148). Interestingly, a recent study has shown these bodies to associate with chromatin in the presence of transcription via an ATPdependent mechanism; upon ATP depletion the bodies exhibited increased mobility that was described by anomalous diffusion (149).

PML BODIES PML nuclear bodies were first identified as nuclear domain 10 (ND10) by autoantibodies recognizing the Sp100 protein $(150,151)$. However, interest in these bodies was significantly increased upon finding that a fusion protein resulting from a $\mathrm{t}(15 ; 17)$ translocation between the PML protein and the retinoic acid receptor- $\alpha$, in acute promyelocytic leukemia, resulted in the disruption of these bodies (152-154). More interestingly, treatment of these individuals with retinoic acid or arsenic trioxide allowed them to go into remission and concomitantly the PML bodies were reformed (152-154). A clear function for these bodies has not yet been established, although roles in transcriptional regulation, as storage sites regulating the levels of active proteins within the nucleus or as sites of active proteolysis, have been pursued [reviewed in (124, 155-157)]. Earlier studies have reported transcription to occur in (158) or on the periphery (159) of these bodies. In addition, the transcriptional coactivator CREB-binding protein (CBP) has been localized to PML bodies in certain cell types (Hep-2, SKN-SH, COS-1, and CHO) (160) and the coactivator p300 and RNA polymerase II have been localized to a subset of PML bodies in some cell types (Hep-2, HeLa, MCF-7, and T24) $(158,161)$. Of particular interest here is the recent finding of a nonrandom association of the gene-rich $\mathrm{MHC}$ on chromosome 6 with PML bodies (120). At least one homologue was associated or overlapping with a PML body in $\sim 42 \%$ of the MRC-5 cells (normal human fibroblasts) examined (120). This association was independent of active tran- 
scription. Interestingly, when several copies of a YAC containing a large proportion of the MHC class II region was stably integrated into the long arm of chromosome 18 in a B-lymphoblastoid cell line, monosomic for the short arm of chromosome 6 and containing a large deletion of the MHC class II region, PML bodies were found to be associated with the MHC class II YAC integration site on chromosome 18, demonstrating the specificity of the association (120). The localization of the transcription factor Sp100, which is involved in the constitutive expression of several genes within the MHC region, to PML bodies has been suggested to support a model in which PML bodies function in transcriptional regulation, perhaps by regulating the soluble pool of transcription factors/ coactivators/corepressors (120). A recent study reexamining Br-UTP incorporation indicated that $\sim 9 \%$ of PML nuclear bodies were associated with transcription sites and this association increased to $51 \%$ upon interferon- $\alpha$ treatment (162). As interferon treatment also increases the number of PML bodies, the direct relationship of these bodies to transcription remains unclear. Counter to an active role in transcription, a subset of PML bodies have been shown to contain HP1 $(163,164)$, a protein associated with silenced chromatin [reviewed in (165)]. In addition, the proteosome inhibitor MG132 induces a PML body/centromere association in a significant number of cells in the G2 phase of the cell cycle (163). Therefore, although it is unclear what role, if any, PML bodies has in transcriptional regulation, their role(s) may be dynamic as cells traverse the cell cycle, and/or different PML bodies within the same nucleus may be involved in different activities. In this regard, a recent study has indicated that a subset of these bodies exhibits ATP-dependent dynamics (166).

HSF1 GRANULES Upon activation of the mammalian heat shock transcription factor 1 (HSF1) by stress, heat shock genes are turned on and HSF1 relocalizes to nuclear bodies termed HSF1 granules (125) or stress-induced Src-activated during mitosis nuclear bodies (SNBs) (126). Although numerous RNA binding proteins have been localized to these granules, transcription does not occur within these nuclear regions. Recently, the granules were shown to bind to a nucleosome-containing subclass of satellite III repeats at the human 9q11-q12 pericentromeric heterochromatin region (125), as well as to the centromeric regions of chromosomes 12 and 15 (126). It is unclear why these specific chromosomal regions are the targets for HSF1 granules and what role these granules have in nuclear metabolism.

POLYCOMB GROUP GRANULES Polycomb group (PcG) protein complexes localize at specific sites in Drosophila called Polycomb response elements (PREs) and in doing so repress genes in cis [reviewed in (167)]. Such elements have not yet been identified in mammalian cells, although homologues of PcG genes have been identified and they appear to function in silencing as do their Drosophila counterparts. Interestingly, human polycomb group (PcG) complex proteins are 
localized in a fine granular distribution throughout the nucleoplasm and are also localized to a varying number of larger domains ranging in size from 0.2 to 1.5 $\mu \mathrm{m}$ in diameter; these domains have been termed PcG granules [reviewed in $(167,168)]$. These granules associate with pericentromeric heterochromatin regions on human chromosome 1 (1q12) and with related sequences on other chromosomes $(167,168)$, and the association is maintained throughout mitosis. However, recently Fakan and co-workers have examined the localization of four members (HPC2, HPH1, BMI1, and RING1) of the human PcG protein family in two cell types and tissue sections by immunoelectron microscopy (169). Although the BMI1 and HPC2 proteins localized to PcG granules, the four proteins were found highly concentrated on the border of condensed chromatin domains in perichromatin nuclear regions. In addition, the PcG proteins were found in the interchromatin space, a region devoid of chromatin, although at a five- to tenfold lower concentration (169). However, these proteins were nearly absent from regions of condensed chromatin. Based on this localization, the authors proposed that loci silenced by PcG proteins are spatially interspersed among transcriptionally active genes (169). These findings argue against a model in which silencing of genes by association with $\mathrm{PcG}$ proteins gives rise to the repositioning of silenced loci inside compact chromatin domains. However, they are in agreement with similar studies in Drosophila in which PcG proteins were found to occupy different positions on polytene chromosomes than HP1, a marker for constituitive heterochromatin (170, 171). Interestingly, several recent studies have identified a role for the Extra Sex Combs (ESC) and Enhancer of Zeste $\mathrm{E}(\mathrm{z})$ PcG protein complex in the trimethylation of lysine- 9 and the methylation of lysine-27 of histone H3 (172-174), resulting in the recruitment of other Polycomb proteins to the histone $\mathrm{H} 3$ amino-terminal tail and mediated silencing.

SEQUESTRATION IN THE CYTOPLASM A significant number of transcription factors are localized in the cytoplasm and only upon activation by a signaling molecule are they transported into the nucleus, where they bind DNA to activate transcription [reviewed in $(175,176)]$. Among such factors are members of a broad array of transcription factor families including STATs (signal transducers and activators of transcription), NF- $\kappa$ Bs (nuclear factors of $\operatorname{Ig} \kappa$ B cells), NFATs (nuclear factors of activated $\mathrm{T}$ cells), and the glucocorticoid receptor. Of this class of factors, perhaps the best-studied at the cell biological level is the glucocorticoid receptor (GR) $(79,107,177)$. Hager and colleagues have utilized a cell line containing a tandem array of $\sim 200$ copies of a mouse mammary tumor virus promoter-driven $h a-v$-ras gene (178) to examine the dynamics of transcription and the association of transcription factors with this endogenous template $(79,107)$. After steroid hormone treatment, a GFP-GR fusion was shown to enter the nuclei and associate with the arrays. The arrays decondensed within $3 \mathrm{~h}$ of hormone treatment and then recondensed over the next $6 \mathrm{~h}$ (178). 


\section{TRANSLATION IN THE NUCLEUS}

The nuclear envelope was thought to functionally demarcate the nuclear compartment where transcription and RNA processing occurs from the cytoplasmic compartment where translation occurs. However, a recent study indicated that a low level of translation occurs within the nucleus (179). When biotin-lysyltRNA $^{\text {lys }}$ or BODIPY-lysyl-tRNA ${ }^{\text {lys }}$ were used to label newly made proteins in vivo, using conditions where nascent polypeptides are extended by $\sim 15$ residues, discrete sites were identified within nucleoli and the nucleoplasm in addition to the prevalent cytoplasmic labeling (179). The nuclear signal represented $15 \%$ of the total incorporation. A similar degree of labeling was observed in isolated nuclei lacking $>95 \%$ of the cytoplasmic ribosomes. Treatment with cycloheximide reduced the nuclear labeling to $4 \%$, and an inhibition of nuclear import did not affect incorporation. In support of these incorporation studies, immunofluorescence analysis has shown that populations of a number of different translation factors including eIF $2 \alpha$, eIF3, eIF4 $\gamma$, eIF4E as well as ribosomal proteins L7 and QM were present in nuclei (179). A portion of the observed nuclear translation was dependent upon concurrent transcription by RNA pol II, and immunogold labeling at the electron microscopic level showed a colocalization of some nascent RNA and nascent polypeptides (179). Based upon these data, the authors suggested that nuclear translation may function in nonsense-mediated decay, a quality control mechanism in which mRNAs are surveyed for the presence of nonsense codons. Support for this possibility comes from studies showing that nonsense mutations can affect pre-mRNA $3^{\prime}$ end processing (180) and result in an accumulation of pre-mRNAs at transcription sites (181). To determine whether ribosomes are recruited to nascent transcripts, Brogna et al. (182) used antibodies to 20 different ribosomal proteins and probes complementary to $18 \mathrm{~S}$ and $28 \mathrm{~S}$ rRNA to demonstrate that the translation apparatus is present at transcription sites on the giant polytene chromosomes of Drosophila melanogaster salivary glands. The presence of both $18 \mathrm{~S}$ as well as $28 \mathrm{~S}$ rRNA suggests the presence of assembled ribosomes (182). Furthermore, these components were concentrated at interbands and were particularly apparent at major puffs. The kinetics of ribosomal protein recruitment to two different ecdysone-inducible loci indicated that the association occurs cotranscriptionally and prior to the completion of pre-mRNA splicing (182).

\section{GENE SILENCING AND NUCLEAR POSITIONING}

Equally important to gene activation is gene silencing, a process by which the inactivity of a gene or set of genes is important to the overall viability of the cell and/or organism or to its differentiation. Two of the best-studied examples of mammalian cell silencing relating to subnuclear positioning are the dosage compensation achieved by X-chromosome inactivation in female mammals 
[reviewed in (183)] and the positioning of inactive genes adjacent to centromeric heterochromatin [reviewed in (184)]. Here, I focus on the relationship of nuclear organization to gene silencing; for an examination of changes in chromatin structure and modifications relating to silencing the reader is referred to other recent reviews $(165,185-187)$.

\section{The Inactive X Chromosome}

As discussed earlier, gene-rich chromosomes are generally located in more internal nuclear regions, whereas gene-poor chromosomes are located in more peripheral areas of the nucleus (34). However, one of the clearest examples of the peripheral localization of a chromosome territory is provided by the inactive $\mathrm{X}$ chromosome in female mammals $(71,188)$. The transcriptionally inactive $\mathrm{X}$ chromosome consists largely of heterochromatic regions and forms a dense nuclear domain, the Barr body, which is often found associated with the nuclear periphery. X-chromosome inactivation results in the transcriptional silencing of several thousand genes and ensures dosage compensation for X-linked gene products between XX females and XY males (189). However, about $15 \%$ of the genes on the human $X$ chromosome escape $X$ inactivation (190). X inactivation is controlled by the $\mathrm{X}$-inactivation center (Xic), which is essential for the developmentally regulated initiation and spread of inactivation along the $\mathrm{X}$ chromosome [reviewed in (183)]. A key player in the cis-acting function of the Xic is the Xist gene. Xist produces a nuclear, untranslated RNA that is expressed uniquely from the inactive $X$ chromosome, coating it in cis (191, 192). In addition, the noncoding antisense transcript Tsix represses Xist expression and is thought to regulate $X$ chromosome choice at the onset of inactivation $(193,194)$. Other features associated with the inactive $\mathrm{X}$ chromosome are its late replication timing, the methylation of $\mathrm{CpG}$ islands, the hypoacetylation of histones $\mathrm{H} 3$ and H4 (195), methylation of H3 lysine-9 as well as hypoacetylation of H3 lysine-9 and hypomethylation of $\mathrm{H} 3$ lysine-4 $(186,196)$, and its enrichment in a histone H2A variant, macro H2A.1 (197). Although these and other differences in the shape, size, and surface properties of the inactive $\mathrm{X}$ chromosome have been reported $(198,199)$, the mechanism behind its commonly observed peripheral localization has not been elucidated.

\section{Repositioning to Pericentric Heterochromatin}

In a pair of now classic studies, Sedat and coworkers and Csink \& Henikoff demonstrated that the brown gene in Drosophila was silenced by contact with centromeric heterochromatin $(200,201)$. The brown ${ }^{\text {Dominant }}\left(b w^{D}\right)$ allele, a null mutation caused by the insertion of a block of heterochromatin within the coding sequences of the brown gene, causes the $b w^{D}$ gene to be misdirected and to associate with centromeric heterochromatin. Most interestingly, in $b w^{+} / b w^{D}$ larva, as a consequence of homologous chromosome pairing, the wild-type allele also localized to the centromere, providing an explanation for the variegated 
inactivation of the normal $b w$ gene (200). Subsequently, this association of silenced genes with centromeric heterochromatin was found to also occur naturally in other cell types. In cycling but not quiescent B cells, transcriptionally active genes are generally positioned away from centromeric heterochromatin, whereas many inactive genes are localized adjacent to heterochromatin domains. For example, the expressed alleles of the $\operatorname{IgH}$ and $\operatorname{Ig} \kappa$ immunoglobulin heavy and light chain genes in lymphocytes occupy nuclear positions away from heterochromatin as opposed to their heterochromatin-associated nonexpressed alleles (202). A similar situation occurs in developing immature thymocytes, where the Rag-1 and TdT genes are downregulated and upon transcriptional termination the genes are repositioned to centromeric regions (203). As the observed repositioning occurs after transcriptional shutdown, locus movement appears to be a result, rather than a cause, of shutdown (203). This repositioning is heritable and stably transmitted through cell division (203). The heritable silencing of genes has also been found in T lymphocytes where CD4 T cells can be induced to develop into Th1 or Th2 cells (T-helper subsets). In this case, the IL-4 (in Th1) and $\gamma$-interferon genes (in Th2) are positioned near centromeric domains (204). Based upon these studies, Fisher and co-workers have proposed a model in which an active target gene localized in a transcriptionally permissive environment is sequestered, upon transcriptional shut-down, to a repressive environment by a hypothetical "recruiter" (205). The recruitment is proposed to be initiated by increased binding of factors to motifs in the target genes, or alternatively, centromere-bound recruiters may access and interact with target genes when motifs previously occupied by transcriptional activators are vacated (205). Of particular interest has been the search for proteins that might mediate the repositioning and/or silencing of these genes. An interesting candidate with regard to the lymphoid lineage is the Ikaros protein. Ikaros is required for normal hemopoiesis, and it shares homology with the Hunchback protein in Drosophila $(206,207)$, which has been implicated in Polycomb recruitment and the establishment of silencing complexes in Drosophila (208, 209). Interestingly, Ikaros has been shown to interact with chromatin remodeling proteins, to colocalize with many inactive genes in lymphocyte nuclei, and to bind to lymphoid-specific promoter sequences as well as to centromere-associated repetitive DNA [reviewed in (184)]. These characteristics are consistent with either a direct role for the Ikaros protein in transcriptional repression or a role as a mediator of silent chromatin. Ikaros is expressed at very low levels and localizes predominantly within the cytoplasm of noncycling B lymphocytes (203). However, following mitogenic activation, Ikaros levels increase and at about 3 days after stimulation Ikaros is highly localized to centromeric clusters, as are transcriptionally repressed genes (203). Smale and co-workers (210) have found that Ikaros proteins compete with the ELF-1 activator for binding to the $\mathrm{D}^{\prime}$ region of the $T d T$ promoter, resulting in TdT downregulation in T-cell lines. Similar findings have been made for a role of the Ikaros protein in silencing the $\lambda 5$ promoter of transgenes in mature B cells (211). 
In an interesting extension of these studies, Francastel et al. (212) assessed the ability of the $\beta$-globin 5'HS2 enhancer to influence silencing and nuclear location of a transgene in mammalian cells. At genomic integration sites where stable expression does not require the presence of an enhancer, transgenes localized away from centromeric heterochromatin regardless of their transcriptional activity. However, at sites where stable expression requires an intact enhancer, active transgenes localized away from centromeric heterochromatin when linked to a functional enhancer (212). Enhancer mutations that impair the ability of the enhancer to suppress silencing also resulted in the transgene remaining close to centromeric heterochromatin, even before the transgene was silenced. Therefore, the same enhancer motifs are required for both suppression of transgene silencing and localization of the transgene away from centromeric heterochromatin (212). Based upon these data, functional enhancers were proposed to antagonize gene silencing by preventing the localization of a gene near centromeric heterochromatin or by recruiting a gene to a nuclear region that is transcriptionally favorable and stably heritable (212). However, changes in chromatin structure are likely also to be involved in gene positioning as localization of the human $\beta$-globin locus away from heterochromatin in mouse erythroleukemia cells correlates with hyperacetylation in the promoter region, even in the absence of transcription (213).

To further assess the interplay between gene silencing and transcriptional activation in heterochromatic nuclear regions, Dillon and co-workers targeted a pre-B-cell specific $\lambda 5$ transgene directly into pericentric heterochromatin in mice (214). The integration resulted in strongly variegated expression in pre-B cells. Analysis of the stability of the expression patterns indicated that the $\lambda 5$ transgene undergoes a reversible switching between the active and repressed states, resembling the telomeric silencing observed in $S$. cerevisiae (215). In both expressing and nonexpressing clones, the transgene remained closely associated with the periphery of the centromeric complex, indicating that activation of the $\lambda 5$ transgene does not require movement away from the heterochromatic region (214). In fibroblasts, a DNase I hypersensitive site (HS1) was shown to be responsible for locating the transgene to the outside of the pericentric heterochromatin complex in the absence of transcription. Deletion of the HS1 site resulted in the $\lambda 5$ transgene being embedded within the pericentric heterochromatin, demonstrating that changes in chromatin structure are directly involved in genome organization (214). However, in pre-B cells, location of the transgene to the outside of the heterochromatin complex was not linked to the HS1 site but instead was related to the dosage of early B cell factor (EBF), as was the ability of the transgene to be transcriptionally activated (214). Therefore, the level of EBF affects both the higher-order chromatin structure and the transcriptional activity of the heterochromatic $\lambda 5$ transgene. Importantly, relocation of this gene away from heterochromatin was not required for transcriptional activation, and transcription of this heterochromatin-associated gene was maintained through multiple cell divisions. This study clearly demonstrated that gene regulation is a 
balance between factor levels/accessibility and chromatin condensation state (214).

Interestingly, just as active genes can be juxtaposed to heterochromatin, inactivation of transcription does not always occur through an association with heterochromatin. In a study examining the expression and nuclear positioning of the $\alpha$ - and $\beta$-globin genes in hemopoietic cells, Brown et al. identified differences in how the nuclear position of these two loci corresponds to their transcriptional activity (216). In primary erythroblasts where both the human $\alpha$ and $\beta$-globin loci are active, they were both positioned away from centromeric heterochromatin (216). In human primary $\mathrm{T}$ lymphocytes and immortalized $\mathrm{B}$ cells, where these genes are not expressed, the $\beta$-globin alleles were localized in close proximity to centromeric DNA, although the $\alpha$-globin locus did not localize close to centromeric DNA in cycling lymphocytes where these genes are inactive. Even when integrated into different chromosomal sites, the $\alpha$-globin genes neither remained discrete from centromeric heterochromatin, nor did they localize with other regions of heterochromatin as demarcated by the localization of HP1 (216). As the $\alpha$-globin locus exhibits characteristics generally attributed to ubiquitously expressed genes, such as a lack of methylation, early replication timing, and DNAse I sensitivity in all tissues, these attributes may influence the chromatin associations and nuclear position of this locus within the nucleus (216). However, in mammalian cells there is no genetic evidence that nuclear position affects the repressed state, and it is not clear whether position is a result or a cause of repression.

\section{Telomeres and the Nuclear Periphery}

In the yeast $S$. cerevisiae, telomeres as well as proteins associated with repressed chromatin (Sir3 and Sir4) have been localized in clusters adjacent to the nuclear envelope [reviewed in (217)]. A fascinating study of chromatin domains in live yeast cells by Gasser and colleagues has shown that telomeres are highly dynamic and move rapidly along the inner nuclear membrane in G1 and S phase cells $(83,218)$. To test whether genes artificially drawn to the yeast nuclear envelope could become transcriptionally silenced, a prior study by Sternglantz and co-workers had shown that a HMR locus with a defective silencer can be silenced by anchoring the locus to the nuclear envelope via the fusion of an integral membrane protein to the GAL4 DNA binding domain (219). As the concentration of Sir proteins is greater at the yeast nuclear periphery, silencing was thought to be favored by artificially placing the locus in a nuclear environment that would be more favorable to silencing. However, since telomeres have been shown to remain peripherally anchored in the absence of Sir proteins, other factors are likely to play a role in this process $(220,221)$. In this regard, several groups have reported that the $\mathrm{Ku}$ heterodimer is bound to telomeres and $\sim 50 \%$ of the telomeres are displaced from the nuclear periphery in $k u$-deficient strains, leading to a reduction in the repression of telomeres as well as silent mating-type (HM) genes (222). As was found for the Sir proteins, anchoring and repression 
can occur, in certain cases, in the absence of $\mathrm{Ku}$ and therefore there is more to the story. Recently, Feuerbach et al. have found that upon disruption of myosinlike protein 2 (Mlp2p), a Ku-binding factor associated with the nuclear periphery, a $20 \%$ increase in the number of telomeric foci was observed, suggesting telomere dispersion (223). Furthermore, these authors have shown that a membrane-anchored reporter to a subtelomeric region or to the silent mating-type locus is sensitive to mutations in Mlps and the nuclear pore protein Nup60. In contrast, repression of natural mating-type loci, which are also associated with peripheral telomeric foci, is not affected by mutations in either Mlps or nuclear pore proteins. Therefore, although it is clear that the peripheral localization of telomeres in yeast coincides with transcriptional repression, multiple mechanisms may be in play to regulate the association of telomeres with the nuclear periphery (218).

\section{The Nuclear Periphery and Gene Activity}

Although strong connections exist between the nuclear periphery and silencing, recently a genetic screen in S. cerevisiae to identify chromatin boundary activities (BAs) has identified a class of BAs that mediate their epigenetic function by specific physical tethering to the NPC (224). Among the BAs identified were the exportins Cse1p, Mex67p, and Los1p. These transport proteins were shown to block spreading of heterochromatin by physical tethering of the $S$. cerevisiae silent mating-type locus HML/boundary trap reporter ADE2 to the Nup2p receptor of the NPC, the major docking site for the exportins on the NPC basket (224). Genetic deletion of Nup2p abolished the BA of the transport proteins directly implicating the NPC in chromatin regulation. Based upon these findings, the authors posit that transportins block the propagation of heterochromatin by tethering of the cis-acting boundary elements to the Nup2p receptor of the NPC basket, thereby initiating a series of chromatin remodeling events (224). Although this reporter assay provides an interesting scenario, it remains to be determined whether genomic loci physically interact in a similar way with the NPC.

\section{REESTABLISHING THE GENE EXPRESSION MACHINERY AFTER MITOSIS}

In higher eukaryotes, mitosis is accompanied by dramatic transformations in the structural organization of both the cytoplasm and nucleus. The onset of mitosis is accompanied by chromatin condensation, breakdown of the nuclear envelope (225), and cessation of bulk cellular transcription (226-228). The constituents of many nuclear domains, such as nuclear speckles and other nuclear bodies, become diffusely distributed throughout the cytoplasm $(89,229-231)$. However, the gene expression machinery must be rapidly reactivated when cells exit from 


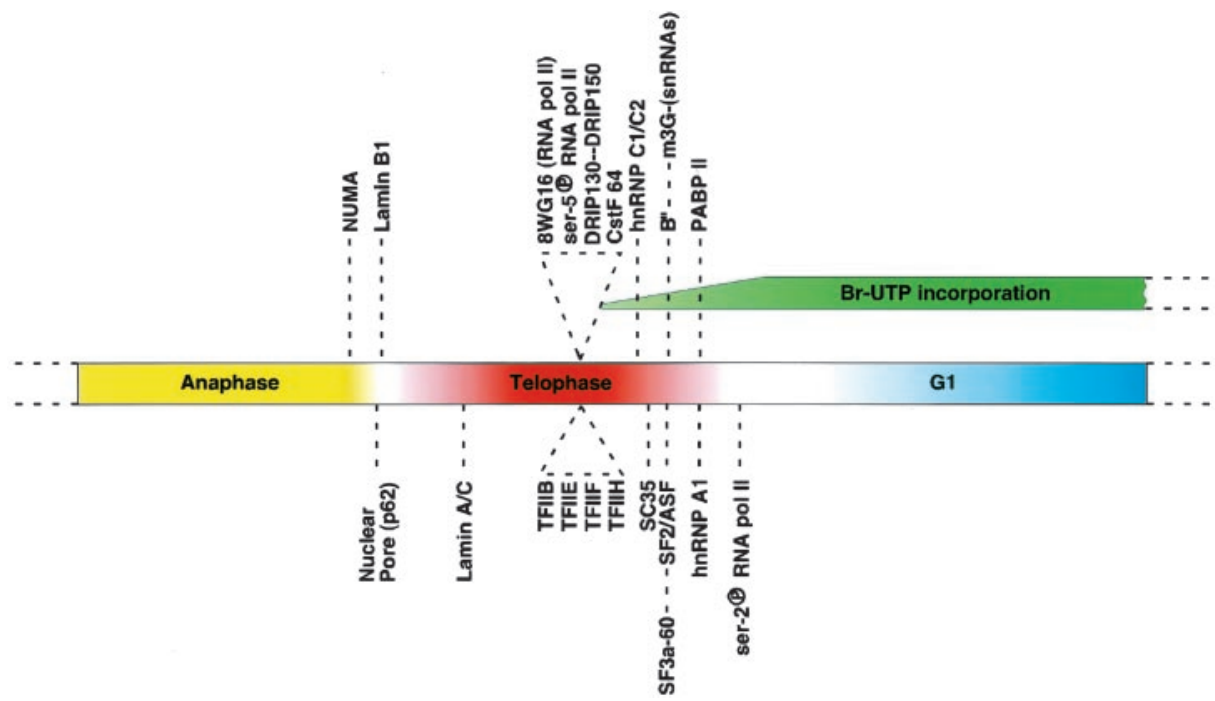

Figure 6 Schematic representation of the order of recruitment of the gene expression machinery into daughter nuclei at the end of mitosis (232).

mitosis. A problem confronted by the mitotic cell is the establishment of the gene expression machinery in daughter nuclei so that these cells become competent to undergo transcription/RNA processing immediately as they exit from mitosis. A recent study has investigated whether components of the gene expression machinery enter postmitotic nuclei individually or as a unitary complex (232). Interestingly, localization studies of numerous RNA pol II transcription and pre-mRNA processing factors revealed a nonrandom and sequential entry of these factors into daughter nuclei after nuclear envelope/lamina formation (Figure 6). The initiation-competent form of RNA pol II and general transcription factors appeared in the daughter nuclei simultaneously, but prior to premRNA processing factors, whereas the elongation competent form of RNA pol II was detected even later (232). The differential entry of these factors rules out the possibility that they are transported as a unitary complex. Furthermore, the differential entry is unlikely to be due to a nuclear retention mechanism based upon substrate binding, as previous studies have shown that pre-mRNA splicing factors (229) as well as RNA pol II (K.V. Prasanth and D.L. Spector, unpublished data not shown) enter daughter nuclei and are maintained in the absence of RNA pol II transcription. Although the mechanism that regulates the sequential recruitment has not been elucidated, it may involve the activation of different importin- $\beta$ family members. Telophase nuclei were competent for transcription and pre-mRNA splicing concomitant with the initial entry of the respective factors. In addition, a low turnover rate of transcription and pre-mRNA splicing factors was found during mitosis, demonstrating that these factors were recycled 
into daughter nuclei as the cells progress through telophase (232). Based upon these data, the authors present a model in which the entry of the RNA pol II gene expression machinery into newly forming daughter nuclei is a staged and ordered process (232). This ordered entry of transcription factors prior to pre-mRNA splicing factors appears to be a general phenomenon as similar results were observed in transformed cells (HeLa) as well as in cells of defined passage number (IMR90). The observed sequential recruitment of proteins into daughter nuclei may establish favorable cues for transcription initiation within the context of the decondensing chromosomes.

\section{PERSPECTIVES}

Progress in the field of chromosome organization and gene regulation has been substantial over the past few years. The ability to visualize individual chromosome territories within the cell has allowed an investigation of the organization of chromosomes within the three-dimensional structure of the cell nucleus. Such studies have indicated that while there is probably not a functionally obligate position for each chromosome within the nucleus, gene complexity and/or chromosome size may influence chromosome position. The overall organization of individual chromosome territories is such that active genes are located throughout the territory and are not restricted to the periphery, as initially posited. In fact, in some cases, large chromosomal loops containing active genes extend outside of the respective chromosome territories $(52,58,59)$. This finding raises concern regarding the interpretation of interphase chromosome paint studies. Based upon our current rate of advancement, it is not unrealistic to anticipate studies that will examine the organization of clusters of adjacent genes within the same chromosome territory in living cells, providing higher-resolution insight into the threedimensional organization of the genome. Are genes repositioned upon their inactivation? Numerous studies have indicated the movement of inactive genes to centromeres, resulting in heritable silencing. However, association with centromeres or the nuclear periphery in mammalian cells in and of itself does not appear sufficient to result in silencing. Increased telomeric repression in yeast has been correlated with anchoring, and silent chromatin was shown to be tethered to the nuclear envelope in a Sir-dependent manner during S-phase (218).

Whereas chromosome territories generally remain in their nuclear neighborhood, particular genes or gene clusters appear to be dynamic and can move via constrained Brownian motion. However, overall movements seem to follow a random walk as no directed movements have been observed $(73,82)$. In some cases, such movements seem to correlate with entry into S-phase or transcriptional activation. Chromosome constraint may be imparted through centromeres and telomeres and/or associations with the nucleolus and nuclear envelope/ lamina. The technology is currently in place for future studies to examine these associations directly in living cells through the cell cycle, and we can expect 
significant insight over the next few years. Surprisingly, diffusion is not the only means of chromatin movement. A recent elegant study in yeast indicated that ATP-dependent movements of chromosomal regions also occur (83). It will be important to determine how widespread such movements are and whether they occur in other cell systems containing different levels of heterochromatin.

RNA polymerase II transcription has been reported to occur at nearly 8000 sites scattered throughout the nucleoplasm (95). Contrary to earlier indications, chromosome territories are accessible to RNA polymerase and transcription factors that are freely diffusing throughout the nuclear space (56). Intriguingly, transcription factors studied to date show rapid exchange rates at transcription sites, with residency times ranging from seconds to minutes, supporting a "hit-and-run" model (107). Various transcription factors are also localized to different nuclear bodies. Although many of these bodies are preferentially associated with specific chromosomal regions, we await future studies to determine the functional relevance of these associations. Given our current ability to visualize genetic loci and factors in living cells, we are on the verge of being able to perform in-depth studies of gene expression with the ability to simultaneously visualize DNA, RNA, and protein in real time. In summary, while there have been many advances in our understanding of the organization and dynamics of the genome and its regulatory factors, one point that stands out is the balance between organization and a degree of plasticity, which may represent an inherent mechanism to ensure proper gene expression.

\section{ACKNOWLEDGMENTS}

I thank Wendy Bickmore, Susan Gasser, Prasanth Kumar, Paula Sacco-Bubulya, and Mona Spector for helpful suggestions on the manuscript. I also thank the members of my laboratory and my wife for bearing with me while I was confined to my office preparing this review. In addition, I thank Wendy Bickmore, Stan Fakan, Roel van Driel, and Pernette Verschure for providing some of the wonderful figures in the manuscript. The nucleus model is a long-standing and continuously evolving project designed in collaboration with Jim Duffy. Research in my laboratory is supported by NIH/NIGMS (GM42694).

\section{The Annual Review of Biochemistry is online at http://biochem.annualreviews.org}

\section{LITERATURE CITED}

1. Hogenesch JB, Ching KA, Batalov S, Su AI, Walker JR, et al. 2001. Cell 106: 413-15

2. Wright FA, Lemon WJ, Zhao WD, Sears R, Zhuo D, et al. 2001. Genome Biol. 2:0025.1-0025.18
3. Lander ES, Linton LM, Birren B, Nusbaum C, Zody MC, et al. 2001. Nature 409:860-921

4. Venter JC, Adams MD, Myers EW, Li PW, Mural RJ, et al. 2001. Science 291: 1304-51 
5. Tsien RY. 1998. Annu. Rev. Biochem. 67:509-44

6. van Roessel P, Brand AH. 2002. Nat. Cell Biol. 4:E15-20

7. Spector DL. 1993. Annu. Rev. Cell Biol. 9:265-315

8. Lamond AI, Earnshaw WC. 1998. Science 280:547-53

9. Matera AG. 1999. Trends Cell Biol. 9:302-9

10. Spector DL. 2001. J. Cell Sci. 114: 2891-93

11. Jenuwein T, Allis CD. 2001. Science 293:1074-80

12. Misteli T. 2001. Science 291:843-47

13. Hernandez-Verdun D, Roussel P, Gebrane-Younes J. 2002. J. Cell. Sci. 115:2265-70

14. Rabl C. 1885. Morphol. Jahrb. 10: 214-330

15. Boveri T. 1909. Arch. Exp. Zellforsch. 3:181-268

16. Deleted in proof

17. McClintock B. 1934. Z. Zellforsch. Mikroskop. Anat. 21:294-328

18. Cremer T, Cremer C, Baumann H, Luedtke EK, Sperling K, et al. 1982. Hum. Genet. 60:46-56

19. Agard DA, Sedat JW. 1983. Nature 302: 676-81

20. Hochstrasser M, Sedat JW. 1987. J. Cell Biol. 104:1455-70

21. Mathog D, Hochstrasser M, Gruenbaum Y, Saumweber H, Sedat JW. 1984. Nature 308:414-21

22. Hilliker AJ. 1985. Genet. Res. 47:13-18

23. Hochstrasser M, Mathog D, Gruenbaum Y, Saumweber H, Sedat JW. 1986. J. Cell Biol. 102:112-23

24. Marshall WF, Dernburg AF, Harmon B, Agard DA, Sedat JW. 1996. Mol. Biol. Cell 7:825-42

25. Trask B, van den Engh G, Pinkel D, Mullikin J, Waldman J, et al. 1988. Hum. Genet. 78:251-59

26. Cremer T, Lichter P, Borden J, Ward DC, Manuelidis L. 1988. Hum. Genet. 80:235-46
27. Borden J, Manuelidis L. 1988. Science 242:1687-91

28. Pinkel D, Gray JW, Trask B, van den Engh G, Fuscoe J, et al. 1986. Cold Spring Harbor Symp. Quant. Biol. 51:151-57

29. Pinkel D, Landegent J, Collins C, Fuscoe J, Segraves R, et al. 1988. Proc. Natl. Acad. Sci. USA 85:9138-42

30. Cremer T, Cremer C. 2001. Nat. Rev. Genet. 2:292-301

31. Nagele R, Freeman T, McMorrow L, Lee H-Y. 1995. Science 270:1831-35

32. Nagele RG, Freeman T, Fazekas J, Lee KM, Thomson Z, Lee HY. 1998. Chromosoma 107:330-38

33. Allison DC, Nestor AL. 1999. J. Cell Biol. 145:1-14

34. Croft JA, Bridger JM, Boyle S, Perry P, Teague P, Bickmore WA. 1999. J. Cell Biol. 145:1119-31

35. Boyle S, Gilchrist S, Bridger JM, Mahy NL, Ellis JA, Bickmore WA. 2001. Hum. Mol. Genet. 10:211-19

36. Bridger JM, Boyle S, Kill IR, Bickmore WA. 2000. Curr. Biol. 10:149-529

37. Wilmut I, Campbell KH. 1998. Science 281:1611

38. Cremer M, von Hase J, Volm T, Brero A, Kreth G, et al. 2001. Chromosome Res. 9:541-67

39. Habermann FA, Cremer M, Walter J, Kreth G, von Hase J, et al. 2001. Chromosome Res. 9:569-84

40. Tanabe H, Muller S, Neusser M, von Hase J, Calcagno E, et al. 2002. Proc. Natl. Acad. Sci. USA 99:4424-29

41. Goldman RD, Gruenbaum Y, Moir RD, Shumaker DK, Spann TP. 2002. Genes Dev. 16:533-47

42. Hutchison CJ, Alvarez-Reyes M, Vaughan OA. 2001. J. Cell Sci. 114: 9-19

43. Wulff K, Parrish JE, Herrmann FH, Wehnert M. 1997. Hum. Mutat. 9: 526-30

44. Wilson KL. 2000. Trends Cell Biol. 10:125-29 
45. Taddei A, Maison C, Roche D, Almouzni G. 2001. Nat. Cell Biol. 3:114-20

46. Ekwall K, Olsson T, Turner BM, Cranston G, Allshire RC. 1997. Cell 91:1021-32

47. Grewal SIS, Bonaduce MJ, Klar AJS. 1998. Genetics 150:563-76

48. Ma H, Siegel AJ, Berezney R. 1999. J. Cell Biol. 146:531-42

49. Maison C, Bailly D, Peters AH, Quivy JP, Roche D, et al. 2002. Nat. Genet. 30:329-34

50. Kurz A, Lampel S, Nickolenko JE, Bradl J, Benner A, et al. 1996. J. Cell Biol. 135:1195-205

51. Dietzel S, Schiebel K, Little G, Edelmann P, Rappold GA, et al. 1999. Exp. Cell Res. 252:363-75

52. Volpi EV, Chevret E, Jones T, Vatcheva R, Williamson J, et al. 2000. J. Cell Sci. 113(Part 9):1565-76

53. Zirbel RM, Mathieu UR, Kurz A, Cremer T, Lichter P. 1993. Chromosome Res. 1:93-106

54. Cremer T, Kurz A, Zirbel R, Dietzel S, Rinke B, et al. 1993. Cold Spring Harbor Symp. Quant. Biol. 58:777-92

55. Abranches R, Beven AF, AragonAlcaide L, Shaw PJ. 1998. J. Cell Biol. 143:5-12

56. Verschure PJ, van Der Kraan I, Manders EM, van Driel R. 1999. J. Cell Biol. 147:13-24

57. Tajbakhsh J, Luz H, Bornfleth H, Lampel S, Cremer C, Lichter P. 2000. Exp. Cell Res. 255:229-37

58. Williams RR, Broad S, Sheer D, Ragoussis J. 2002. Exp. Cell Res. 272:163-75

59. Park PC, De Boni U. 1998. Chromosoma 107:87-95

60. Nogami M, Kohda A, Taguchi H, Nakao M, Ikemura T, Okumura K. 2000. J. Cell Sci. 113(Part 12):2157-65

61. Mahy NL, Perry PE, Gilchrist S, Baldock RA, Bickmore WA. 2002. J. Cell Biol. 157:579-89
62. Kent J, Lee M, Schedl A, Boyle S, Fantes J, et al. 1997. Genomics 42: 260-67

63. Gawin B, Niederfuhr A, Schumacher N, Hummerich H, Little PF, Gessler M. 1999. Genome Res. 9:1074-86

64. Kleinjan DA, Seawright A, Elgar G, van Heyningen V. 2002. Mamm. Genome 13:102-7

65. Belmont AS, Dietzel S, Nye AC, Strukov YG, Tumbar T. 1999. Curr. Opin. Cell Biol. 11:307-11

66. Tsukamoto $\mathrm{T}$, Hashiguchi $\mathrm{N}$, Janicki SM, Tumbar T, Belmont AS, Spector DL. 2000. Nat. Cell Biol. 2:871-78

67. Ferguson M, Ward DC. 1992. Chromosoma 101:557-65

68. Manuelidis L. 1985. Ann. NY Acad. Sci. 450:205-21

69. Csink AK, Henikoff S. 1998. J. Cell Biol. 143:13-22

70. Shelby RD, Hahn KM, Sullivan KF. 1996. J. Cell Biol. 135:545-57

71. Barr ML, Bertram EG. 1949. Nature 163:676-77

72. Abney JR, Cutler B, Fillbach ML, Axelrod D, Scalettar BA. 1997. J. Cell Biol. 137:1459-68

73. Vazquez J, Belmont AS, Sedat JW. 2001. Curr. Biol. 11:1227-39

74. Zink D, Cremer T. 1998. Curr. Biol. 8:321-24

75. Manders EM, Kimura H, Cook PR. 1999. J. Cell Biol. 144:813-21

76. Robinett CC, Straight A, Li G, Willhelm C, Sudlow G, et al. 1996. J. Cell Biol. 135:1685-700

77. Li G, Sudlow G, Belmont AS. 1998. J. Cell Biol. 140:975-89

78. Tumbar T, Sudlow G, Belmont AS. 1999. J. Cell Biol. 145:1341-54

79. Muller WG, Walker D, Hager GL, McNally JG. 2001. J. Cell Biol. 154: 33-48

80. Tumbar T, Belmont AS. 2001. Nat. Cell Biol. 3:134-39

81. Chubb JR, Boyle S, Perry P, Bickmore WA. 2002. Curr. Biol. 12:439-45 
82. Marshall WF, Straight A, Marko JF, Swedlow J, Dernburg A, et al. 1997. Curr. Biol. 7:930-39

83. Heun P, Laroche T, Shimada K, Furrer P, Gasser SM. 2001. Science 294: 2181-86

84. Zink D, Cremer T, Saffrich R, Fischer R, Trendelenburg MF, et al. 1998. Hum. Genet. 102:241-51

85. Nakayasu H, Berezney R. 1989. J. Cell Biol. 108:1-11

86. Fakan S, Bernhard W. 1971. Exp. Cell Res. 67:129-41

87. Fakan S, Nobis P. 1978. Exp. Cell Res. 113:327-37

88. Fakan S, Puvion E, Spohr G. 1976. Exp. Cell Res. 99:155-64

89. Spector DL, Fu X-D, Maniatis T. 1991. EMBO J. 10:3467-81

90. Cmarko D, Verschure PJ, Martin TE, Dahmus ME, Krause S, et al. 1999. Mol. Biol. Cell 10:211-23

91. Fakan S. 1994. Trends Cell Biol. 4:86-90

92. Fakan S, Puvion E. 1980. Int. Rev. Cytol. 65:255-99

93. Jackson DA, Hassan AB, Errington RJ, Cook PR. 1993. EMBO J. 12:1059-65

94. Wansink DG, Schul W, van der Kraan I, van Steensel B, van Driel R, de Jong L. 1993. J. Cell Biol. 122:283-93

95. Pombo A, Jackson DA, Hollinshead M, Wang Z, Roeder RG, Cook PR. 1999. EMBO J. 18:2241-53

96. Iborra FJ, Pombo A, Jackson DA, Cook PR. 1996. J. Cell Sci. 109:1427-36

97. Jackson DA, Iborra FJ, Manders EM, Cook PR. 1998. Mol. Biol. Cell 9:1523-36

98. Davie JR. 1995. Int. Rev. Cytol. 162A: 191-250

99. Nakayasu H, Berezney R. 1991. Proc. Natl. Acad. Sci. USA 88:10312-16

100. Berezney R. 2002. Adv. Enzyme Regul. 42:39-52

101. Berezney R, Mortillaro MJ, Ma H, Wei XY, Samarabandu J. 1995. Int. Rev. Cytol. 162A:1-65
102. Stein GS, van Wijnen AJ, Stein J, Lian JB, Montecino M. 1995. Int. Rev. Cytol. 162A:251-78

103. Spann TP, Goldman AE, Wang C, Huang S, Goldman RD. 2002. J. Cell Biol. 156:603-8

104. Cremer T, Kreth G, Koester H, Fink RH, Heintzmann R, et al. 2000. Crit. Rev. Eukaryot. Gene Expr. 10:179-212

105. Lemon B, Tjian R. 2000. Genes Dev. 14:2551-69

106. Hager GL, Elbi C, Becker M. 2002. Curr. Opin. Genet. Dev. 12:137-41

107. McNally JG, Muller WG, Walker D, Wolford R, Hager GL. 2000. Science 287:1262-65

108. Stenoien DL, Patel K, Mancini MG, Dutertre M, Smith CL, et al. 2001. Nat. Cell Biol. 3:15-23

109. Chen D, Hinkley CS, Henry RW, Huang S. 2002. Mol. Biol. Cell 13:276-84

110. Kimura H, Cook PR. 2001. J. Cell Biol. 153:1341-53

111. Fletcher TM, Ryu BW, Baumann CT, Warren BS, Fragoso G, et al. 2000. Mol. Cell Biol. 20:6466-75

112. Deleted in proof

113. Stenoien DL, Nye AC, Mancini MG, Patel K, Dutertre M, et al. 2001. Mol. Cell Biol. 21:4404-12

114. Freeman BC, Yamamoto KR. 2002. Science 296:2232-35

115. Freeman BC, Felts SJ, Toft DO, Yamamoto KR. 2000. Genes Dev. 14:422-34

116. Pombo A, Cuello P, Schul W, Yoon J-B, Roeder RG, et al. 1998. EMBO J. 17:1768-78

117. Grande MA, van der Kraan I, de Jong L, van Driel R. 1997. J. Cell Sci. 110: 1781-91

118. Elefanty A, Antoniou M, Custodio N, Carmo-Fonseca M, Grosveld F. 1996. EMBO J. 15:319-33

119. Mancini MG, Liu B, Sharp ZD, Mancini MA. 1999. J. Cell. Biochem. 72:322-38 120. Shiels C, Islam SA, Vatcheva R, Sasieni 
P, Sternberg MJ, et al. 2001. J. Cell Sci. 114:3705-16

121. Stein GS, van Wijnen AJ, Stein JL, Lian JB, Pockwinse S, McNeil S. 1998. J. Cell. Biochem. 70:200-12

122. Gall JG. 2000. Annu. Rev. Cell Dev. Biol. 16:273-300

123. Sleeman JE, Lamond AI. 1999. Curr. Biol. 9:1065-74

124. Zhong S, Salomoni P, Pandolfi PP. 2000. Nat. Cell Biol. 2:E85-90

125. Jolly C, Konecny L, Grady DL, Kutskova YA, Cotto JJ, et al. 2002. J. Cell Biol. 156:775-81

126. Denegri M, Moralli D, Rocchi M, Biggiogera M, Raimondi E, et al. 2002. Mol. Biol. Cell 13:2069-79

127. Bregman DB, Du L, van der Zee S, Warren SL. 1995. J. Cell Biol. 129:287-98

128. Mortillaro MJ, Blencowe BJ, Wei X, Nakayasu H, Du L, et al. 1996. Proc. Natl. Acad. Sci. USA 93:8253-57

129. Misteli T, Spector DL. 1998. Curr. Opin. Cell Biol. 10:323-31

130. Huang S, Spector DL. 1996. J. Cell Biol. 131:719-32

131. Jiménez-García LF, Spector DL. 1993. Cell 73:47-59

132. Mintz PJ, Patterson SD, Neuwald AF, Spahr CS, Spector DL. 1999. EMBO J. 18:4308-20

133. Price DH. 2000. Mol. Cell Biol. 20:2629-34

134. Herrmann CH, Mancini MA. 2001. J. Cell Sci. 114:1491-503

135. Lis JT, Mason P, Peng J, Price DH, Werner J. 2000. Genes Dev. 14:792-803

136. Jordan P, Cunha C, Carmo-Fonseca M. 1997. Mol. Biol. Cell 8:1207-17

137. Pessler F, Pendergrast PS, Hernandez N. 1997. Mol. Cell Biol. 17:3786-98

138. Pendergrast PS, Wang C, Hernandez N, Huang S. 2002. Mol. Biol. Cell 13:915-29

139. Spector DL. 1990. Proc. Natl. Acad. Sci. USA 87:147-51
140. Hendzel MJ, Kruhlak MJ, Bazett-Jones DP. 1998. Mol. Biol. Cell 9:2491-507

141. Hock R, Wilde F, Scheer U, Bustin M. 1998. EMBO J. 17:6992-7001

142. Lobo SM, Hernandez N. 1994. In Transcription Mechanisms and Regulation, ed. RC Conaway, JW Conaway, pp. 127-59. New York: Raven

143. Saunders WS, Cooke CA, Earnshaw WC. 1991. J. Cell Biol. 115:919-31

144. Ramón y Cajal S. 1903. Trab. Lab. Invest. Biol. 2:129-221

145. Matera AG. 1998. J. Cell. Biochem. 70:181-92

146. Frey MR, Matera AG. 1995. Proc. Natl. Acad. Sci. USA 92:5915-19

147. Jacobs EY, Frey MR, Wu W, Ingledue TC, Gebuhr TC, et al. 1999. Mol. Biol. Cell 10:1653-63

148. Frey MR, Bailey AD, Weiner AM, Matera AG. 1999. Curr. Biol. 9:126-35

149. Platani M, Goldberg I, Lamond AI, Swedlow JR. 2002. Nat. Cell Biol. 4:502-8

150. Ascoli CA, Maul GG. 1991. J. Cell Biol. 112:785-95

151. Szostecki C, Guldner HH, Netter HJ, Will H. 1990. J. Immunol. 145:4338-47

152. Dyck JA, Maul GG, Miller WH Jr, Chen JD, Kakizuka A, Evans RM. 1994. Cell 76:333-43

153. Koken MH, Puvion-Dutilleul F, Guillemin MC, Viron A, Linares-Cruz G, et al. 1994. EMBO J. 13:1073-83

154. Weis K, Rambaud S, Lavau C, Jansen J, Carvalho T, et al. 1994. Cell 76:345-56

155. Borden KL. 2002. Mol. Cell Biol. 22:5259-69

156. Negorev D, Maul GG. 2001. Oncogene 20:7234-42

157. Lallemand-Breitenbach V, Zhu J, Puvion F, Koken M, Honore N, et al. 2001. J. Exp. Med. 193:1361-71

158. LaMorte VJ, Dyck JA, Ochs RL, Evans RM. 1998. Proc. Natl. Acad. Sci. USA 95:4991-96

159. Boisvert FM, Hendzel MJ, Bazett-Jones DP. 2000. J. Cell Biol. 148:283-92 
160. Boisvert FM, Kruhlak MJ, Box AK, Hendzel MJ, Bazett-Jones DP. 2001. J. Cell Biol. 152:1099-106

161. von Mikecz A, Zhang S, Montminy M, Tan EM, Hemmerich P. 2000. J. Cell Biol. 150:265-73

162. Fuchsova B, Novak P, Kafkova J, Hozak P. 2002. J. Cell Biol. 158:463-73

163. Everett RD, Earnshaw WC, Pluta AF, Sternsdorf T, Ainsztein AM, et al. 1999. J. Cell Sci. 112:3443-54

164. Seeler JS, Marchio A, Sitterlin D, Transy C, Dejean A. 1998. Proc. Natl. Acad. Sci. USA 95:7316-21

165. Eissenberg JC, Elgin SC. 2000. Curr. Opin. Genet. Dev. 10:204-10

166. Muratani M, Gerlich D, Janicki SM, Gebhard M, Eils R, Spector DL. 2002. Nat. Cell Biol. 4:106-10

167. Brock HW, van Lohuizen M. 2001. Curr. Opin. Genet. Dev. 11:175-81

168. Saurin AJ, Shiels C, Williamson J, Satijn DP, Otte AP, et al. 1998. J. Cell Biol. 142:887-98

169. Cmarko D, Verschure PJ, Otte AR, van Driel R, Fakan S. 2003. J. Cell Sci. 116:335-43

170. Sinclair DA, Milne TA, Hodgson JW, Shellard J, Salinas CA, et al. 1998. Development 125:1207-16

171. Buchenau P, Hodgson J, Strutt H, ArndtJovin DJ. 1998. J. Cell Biol. 141:469-81

172. Czermin B, Melfi R, McCabe D, Seitz V, Imhof A, Pirrotta V. 2002. Cell 111: 185-96

173. Muller J, Hart CM, Francis NJ, Vargas ML, Sengupta A, et al. 2002. Cell 111: 197-208

174. Cao R, Wang L, Wang HY, Xia L, Erdjument-Bromage $\mathrm{H}$, et al. 2002. Science 298:1039-43

175. Kaffman A, O’Shea EK. 1999. Аnnu. Rev. Cell Dev. Biol. 15:291-339

176. DeFranco DB. 1999. Cell Biochem. Biophys. 30:1-24

177. Hager GL, Fletcher TM, Xiao N, Baumann CT, Muller WG, McNally JG. 2000. Biochem. Soc. Trans. 28:405-10
178. Kramer PR, Fragoso G, Pennie W, Htun H, Hager GL, Sinden RR. 1999. J. Biol. Chem. 274:28590-97

179. Iborra FJ, Jackson DA, Cook PR. 2001. Science 293:1139-42

180. Brogna S. 1999. RNA 5:562-73

181. Muhlemann O, Mock-Casagrande CS, Wang J, Li S, Custodio N, et al. 2001. Mol. Cell 8:33-43

182. Brogna S, Sato TA, Rosbash M. 2002. Mol. Cell 10:93-104

183. Avner P, Heard E. 2001. Nat. Rev. Genet. 2:59-67

184. Fisher AG, Merkenschlager M. 2002. Curr. Opin. Genet. Dev. 12:193-97

185. Hwang KK, Eissenberg JC, Worman HJ. 2001. Proc. Natl. Acad. Sci. USA 98:11423-27

186. Heard E, Rougeulle C, Arnaud D, Avner P, Allis CD, Spector DL. 2001. Cell 107:727-38

187. Strahl BD, Allis CD. 2000. Nature 403: 41-45

188. Barr ML, Carr DH. 1962. Acta Cytol. 6:34-45

189. Lyon MF. 1961. Nature 190:372-73

190. Carrel L, Cottle AA, Goglin KC, Willard HF. 1999. Proc. Natl. Acad. Sci. USA 96:14440-44

191. Brockdorff N, Ashworth A, Kay GF, Cooper P, Smith S, et al. 1991. Nature 351:329-31

192. Brown CJ, Hendrich BD, Rupert JL, Lafreniere RG, Xing Y, et al. 1992. Cell 71:527-42

193. Debrand E, Chureau C, Arnaud D, Avner P, Heard E. 1999. Mol. Cell Biol. 19:8513-25

194. Lee JT, Lu N. 1999. Cell 99:47-57

195. Jeppesen P, Turner BM. 1993. Cell 74:281-89

196. Boggs BA, Cheung P, Heard E, Spector DL, Chinault AC, Allis CD. 2002. Nat. Genet. 30:73-76

197. Costanzi C, Pehrson JR. 1998. Nature 393:599-601

198. Clemson CM, McNeill JA, Willard HF, 
Lawrence JB. 1996. J. Cell Biol. 132: 259-75

199. Eils R, Dietzel S, Bertin E, Schröck E, Speicher MR, et al. 1996. J. Cell Biol. 135:1427-40

200. Dernburg AF, Broman KW, Fung JC, Marshall WF, Philips J, et al. 1996. Cell 85:745-59

201. Csink AK, Henikoff S. 1996. Nature 381:529-31

202. Skok JA, Brown KE, Azuara V, Caparros ML, Baxter J, et al. 2001. Nat. Immunol. 2:848-54

203. Brown KE, Baxter J, Graf D, Merkenschlager M, Fisher AG. 1999. Mol. Cell 3:207-17

204. Grogan JL, Mohrs M, Harmon B, Lacy DA, Sedat JW, Locksley RM. 2001. Immunity 14:205-15

205. Brown KE, Guest SS, Smale ST, Hahm K, Merkenschlager M, Fisher AG. 1997. Cell 91:845-54

206. Georgopoulos K, Moore DD, Derfler B. 1992. Science 258:808-12

207. Hahm K, Ernst P, Lo K, Kim GS, Turck C, Smale ST. 1994. Mol. Cell Biol. 14:7111-23

208. Zhang CC, Bienz M. 1992. Proc. Natl. Acad. Sci. USA 89:7511-15

209. Poux S, Kostic C, Pirrotta V. 1996. EMBO J. 15:4713-22

210. Trinh LA, Ferrini R, Cobb BS, Weinmann AS, Hahm K, et al. 2001. Genes Dev. 15:1817-32

211. Sabbattini P, Lundgren M, Georgiou A, Chow C, Warnes G, Dillon N. 2001. EMBO J. 20:2812-22

212. Francastel C, Walters MC, Groudine M, Martin DI. 1999. Cell 99:259-69

213. Schubeler D, Francastel C, Cimbora DM, Reik A, Martin DI, Groudine M. 2000. Genes Dev. 14:940-50

214. Lundgren M, Chow CM, Sabbattini P, Georgiou A, Minaee S, Dillon N. 2000. Cell 103:733-43
215. Gottschling DE, Aparicio OM, Billington BL, Zakian VA. 1990. Cell 63:751-62

216. Brown KE, Amoils S, Horn JM, Buckle VJ, Higgs DR, et al. 2001. Nat. Cell Biol. 3:602-6

217. Hediger F, Gasser SM. 2002. Nat. Cell Biol. 4:E53-55

218. Hediger F, Neumann FR, Van Houwe G, Dubrana K, Gasser SM. 2002. Curr. Biol. 12:2076-89

219. Andrulis ED, Neiman AM, Zappulla DC, Sternglanz R. 1998. Nature 394:592-95

220. Gotta M, Laroche T, Formenton A, Maillet L, Scherthan H, Gasser SM. 1996. J. Cell Biol. 134:1349-63

221. Tham WH, Wyithe JS, Ferrigno PK, Silver PA, Zakian VA. 2001. Mol. Cell 8:189-99

222. Laroche T, Martin SG, Gotta M, Gorham HC, Pryde FE, et al. 1998. Curr. Biol. 8:653-56

223. Feuerbach F, Galy V, Trelles-Sticken E, Fromont-Racine M, Jacquier A, et al. 2002. Nat. Cell Biol. 4:214-21

224. Ishii K, Arib G, Lin C, Van Houwe G, Laemmli UK. 2002. Cell 109:551-62

225. John S, Workman JL. 1998. BioEssays 20:275-79

226. Gottesfeld JM, Forbes DJ. 1997. Trends Biochem. Sci. 22:197-202

227. Prescott DM, Bender MA. 1962. Exp. Cell Res. 26:260-68

228. Johnson LH, Holland JJ. 1965. J. Cell Biol. 27:565-74

229. Ferreira JA, Carmo-Fonseca M, Lamond AI. 1994. J. Cell Biol. 126:11-23

230. Reuter R, Appel B, Rinke J, Lührmann R. 1985. Exp. Cell Res. 159:63-79

231. Spector DL, Smith HC. 1986. Exp. Cell Res. 163:87-94

232. Prasanth KV, Sacco-Bubulya P, Prasanth SG, Spector DL. 2003. Mol. Biol. Cell www.molbiolcell.org/cgi/doi/10.1091/ mbc.E02-10-0669 
A 1 Annual Review of Biochemistry

\section{CONTENTS}

WITH THE HELP OF GIANTS, Irwin Fridovich

THE ROTARY MOTOR OF BACTERIAL FLAGELLA, Howard C.

Berg

ALIPHATIC EPOXIDE CARBOXYLATION, Scott A. Ensign, Jeffrey R.

Allen

FUNCTION AND STRUCTURE OF COMPLEX II OF THE

RESPIRATORY CHAIN, Gary Cecchini

PROTEIN DISULFIDE BOND FORMATION IN PROKARYOTES,

Hiroshi Kadokura, Federico Katzen, Jon Beckwith

THE ENZYMES, REGULATION, AND GENETICS OF BILE ACID

SYNTHESIS, David W. Russell

PROTEIN-LIPID INTERPLAY IN FUSION AND FISSION OF

BIOLOGICAL MEMBRANES, Leonid V. Chernomordik, Michael M.

Kozlov

175

THE MANY FACES OF VITAMIN B12: CATALYSIS BY

COBALAMIN-DEPENDENT ENZYMES, Ruma Banerjee, Stephen W.

Ragsdale

209

SEMISYNTHESIS OF PROTEINS BY EXPRESSED PROTEIN

LIGATION, Tom W. Muir

249

MECHANISMS OF ALTERNATIVE PRE-MESSENGER RNA

SPLICING, Douglas L. Black

291

COVALENT TRAPPING OF PROTEIN-DNA COMPLEXES, Gregory

L. Verdine, Derek P.G. Norman

337

TEMPORAL AND SPATIAL REGULATION IN PROKARYOTIC CELL CYCLE PROGRESSION AND DEVELOPMENT, Kathleen $R$. Ryan, Lucy Shapiro

367

SIGNALS FOR SORTING OF TRANSMEMBRANE PROTEINS TO ENDOSOMES AND LYSOSOMES, Juan S. Bonifacino, Linton M.

Traub

395

THE RNA POLYMERASE II CORE PROMOTER, Stephen T. Smale, James T. Kadonaga

449

THE ESTABLISHMENT, INHERITANCE, AND FUNCTION OF SILENCED CHROMATIN IN SACCHAROMYCES CEREVISIAE, Laura N. Rusche, Ann L. Kirchmaier, Jasper Rine

CHALLENGES IN ENZYME MECHANISM AND ENERGETICS, Daniel A. Kraut, Kate S. Carroll, Daniel Herschlag

THE DYNAMICS OF CHROMOSOME ORGANIZATION AND GENE REGULATION, David L. Spector

TRK RECEPTORS: ROLES IN NEURONAL SIGNAL

TRANSDUCTION, Eric J. Huang, Louis F. Reichardt 
A GENETIC APPROACH TO MAMMALIAN GLYCAN FUNCTION, John B. Lowe, Jamey D. Marth

THE RNA POLYMERASE II ELONGATION COMPLEX, Ali

Shilatifard, Ronald C. Conaway, Joan Weliky Conaway

693

DYNAMICS OF CELL SURFACE MOLECULES DURING T CELL RECOGNITION, Mark M. Davis, Michelle Krogsgaard, Johannes B. Huppa, Cenk Sumen, Marco A. Purbhoo, Darrell J. Irvine, Lawren C. Wu, Lauren Ehrlich

BIOLOGY OF THE P21-ACTIVATED KINASES, Gary M. Bokoch

Proteomics, Heng Zhu, Metin Bilgin, Michael Snyder

THE STRUCTURAL BASIS OF LARGE RIBOSOMAL SUBUNIT

FUNCTION, Peter B. Moore, Thomas A. Steitz 